Bull. Fac. Agric., Cairo Univ., 71: 37-48 (2020).

\title{
FAMILY QUALITY OF LIFE AND ITS IMPACT ON THE SOCIAL BEHAVIOR OF RURAL WOMEN IN NEW VALLEY GOVERNORATE
}

(Received: 29.6.2020)

\author{
By \\ H. G. Shaaban \\ Department of Social Studies - Desert Research Center, Cairo, Egypt
}

\begin{abstract}
Search target, This study is an attempt to:identify the personal characteristics of rural women in the study sample,measuring the quality of family life for rural women, measuring the social behavior of rural women, determine the significance of the relationship between the personal variables of the respondents and the quality of family life, determine the significance of the relationship between the personal variables of the respondents and social behavior,determine the significance of the relationship between the quality of family life and the social behavior of the respondents, and to come up with a set of findings and recommendations that could form the basis for building strategies to improve the quality of family life and social behavior of rural women in the Arab Republic of Egypt.

The present study was conducted in the New Valley Governorate (Kharga - Dakhla - Balat Paris).The overall size was 117,189 females. The sample size was 384 respondents according to the Morgan table to determine the sample size, which is a random sample. The data were collected by the personal interviews with the respondents by through questionnaire designed for this purpose during January and February 2020, and the researcher used to tabulate the data and analyze the tables of numerical inventory, percentages, and conformity coefficient (Ka2), simple correlation coefficient, $\mathrm{T}$ Test..The most important results were the following: With regard to the specifications of the research sample, approximately half of the respondents were of ages 40 to less than 50 between and their rate is $49.5 \%$, more than half of the respondents are of medium qualifications campaign with their percentage is $58.6 \%$, more than two-thirds of the respondents were housewives $(66.9 \%)$, more than two-thirds of the respondents were married (90.9\%), that more than two-thirds of the respondents in the category of family members were between 1 for less than 5 and they reached $81.8 \%$, more than two-thirds of the respondents with income ranges what between 1000 to less than 3000 L.E. (86.2\%), and more than two-thirds of the respondents say the size of agricultural tenure from 1 to less than 5 acres, $(91.9 \%)$.With regard to the quality of family life and its impact on the social behavior of the respondents, the results show the following:

- There is a relationship between the quality of family life and its impact on the social behavior of the respondents, and that more than two thirds of the respondents (78.6\%) their social behavior is positive. - There is a relationship between all variables studied, profession, educational qualification, marital status, monthly source of income, type of tenure, member of social organizations, exposure to mass communication methods of the respondents, and the quality of family life. The value of the Kay square, calculated respectively $337.041,675.168,340.390,549.946,367.490,176.666,540.016$ which is greater than its tabular counterpart. The value of the simple correlation coefficient of the holding size was 0.106 , which is greater than its tabular counterpart .

- There was no significant correlation between the variable of age, the monthly income, the number of family members of the respondents, and the quality of family life, as the value of the simple correlation coefficient, respectively, reached 086., 087., 021, which is lower than its tabular counterpart .
\end{abstract}

Key words : quality of life, social behavior, rural women. 
جودة الحياة الأسرية وأثرها على السلوك الاجتماعى للمرأة الريفية بمحافظة الوادى الجديد

حسن جلال شعبان

قسم الدراسات الاجتماعية - مركز بحوث الصحراء - القاهرة ـ مصر

ملخص

إستهـف هذا البحث ـ التعرف السمات الثخصية للمر أة الريفية بعينة الدراسة ، قياس جودة الحياة الأسرية للمر أة الريفية،

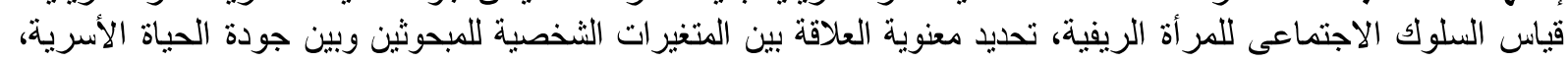

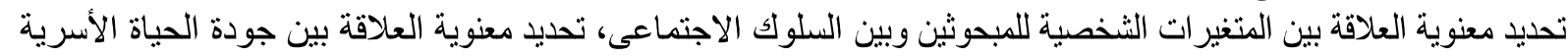

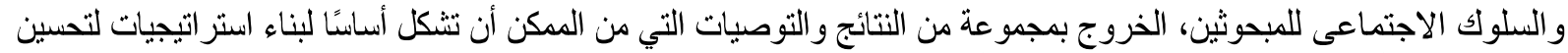

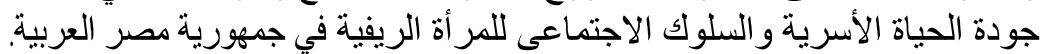

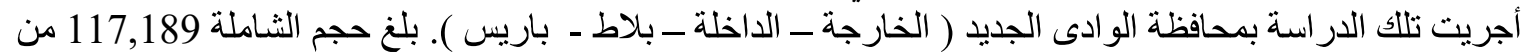

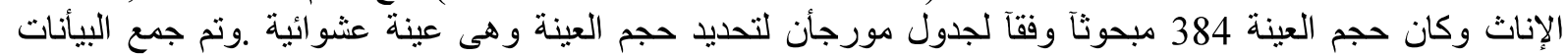

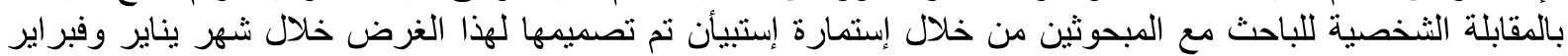

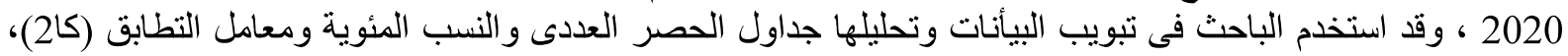

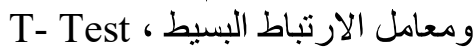

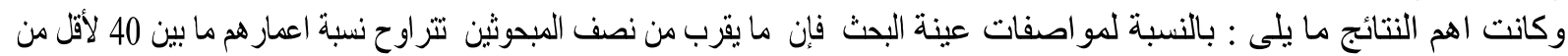

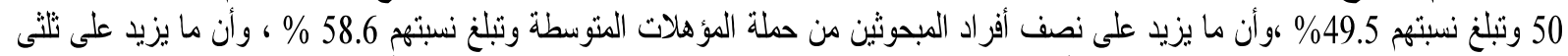

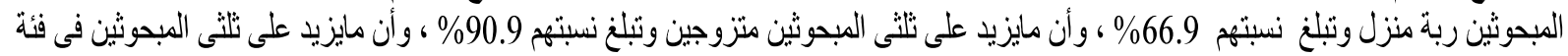

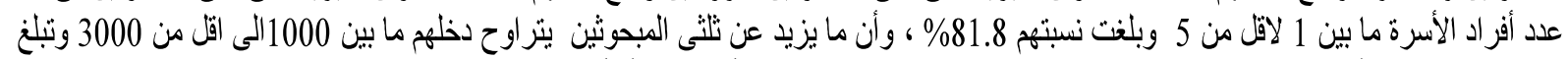

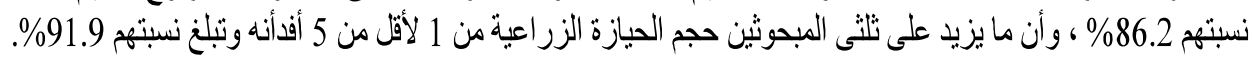

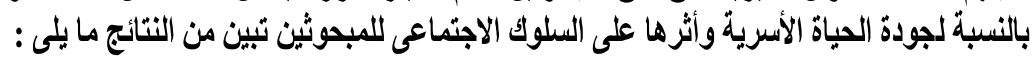

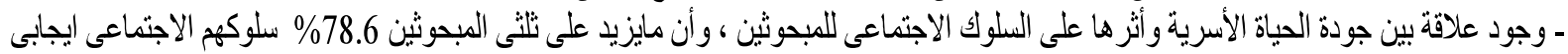

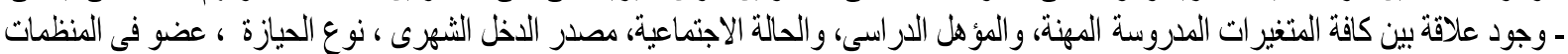

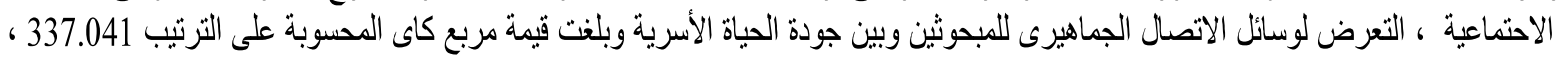

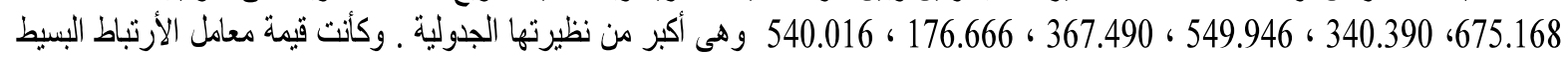

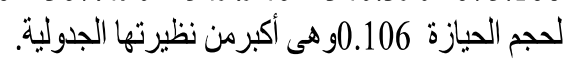

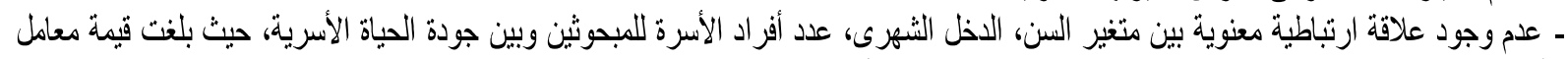

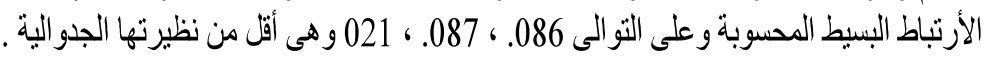

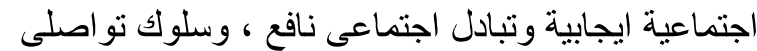
هادف تتحقق فيه الاسس الاجتماعية لجودة الحياة.

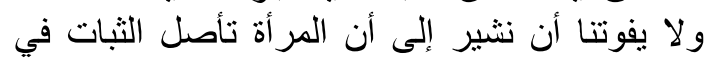

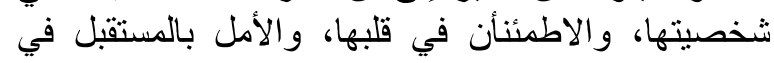

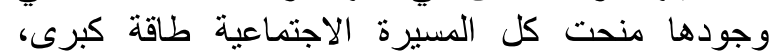

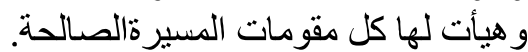

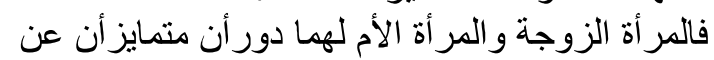

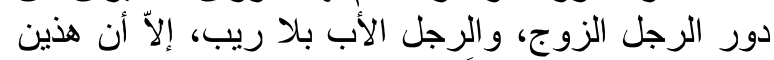

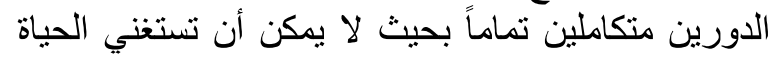
عن هذين الدورين، بمقار عدم امكأن استبدال أحدهما بالآخر تماماً.

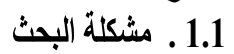

المر أة تارة ننظر إليها بوصفها أنسأناً فعالاً فى الحياة

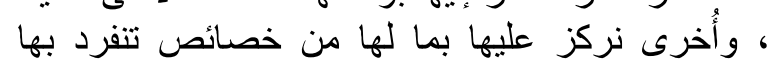

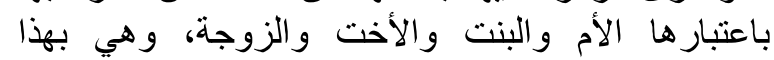
الاعتبار تمتاز على الرجل بما تحمله من طاقات عاطفية

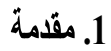

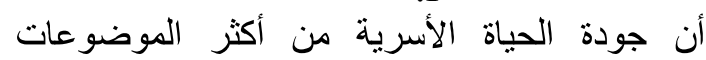

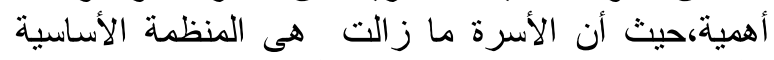

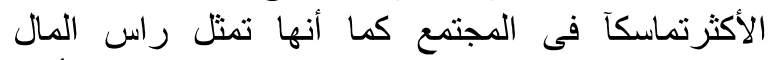

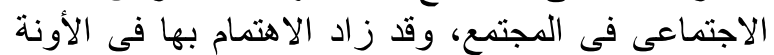

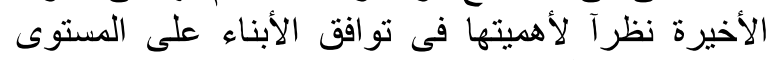

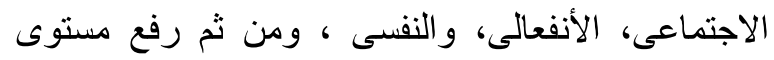

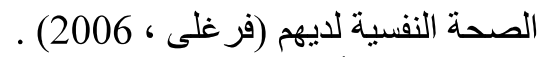

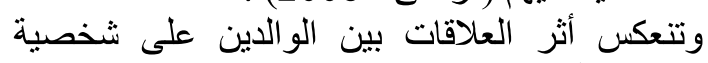

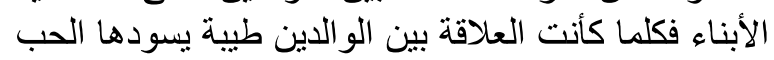

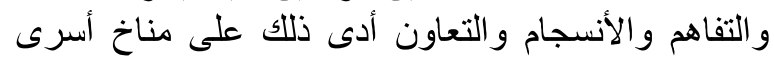

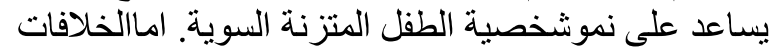

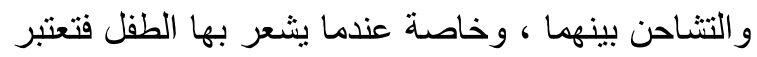

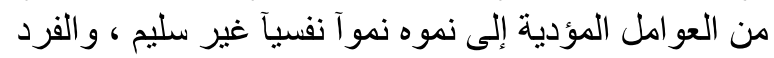

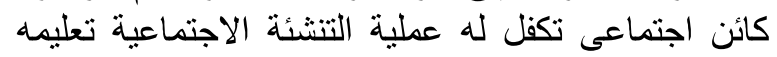

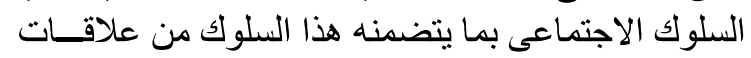


و السن ، و الدخل ، و عدد أفراد الاسرة ، وحجم الحيازة

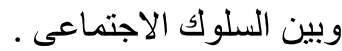

3- لاتوجد علاقة بين جودة الاجنياعى الحياة الأسرية والسلوك الاجتماعى للمبحوثين

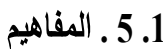

Family quality of life : مفهوم جودة الحياة الأسرية المفية

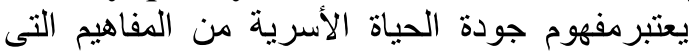

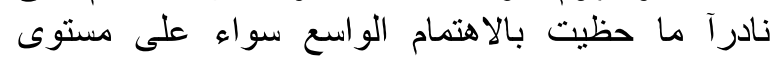

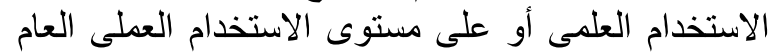

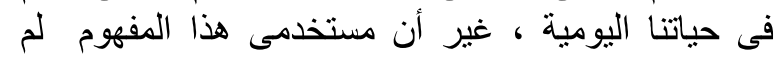

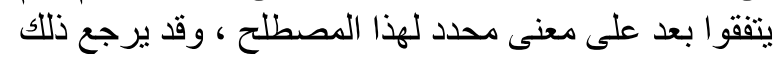

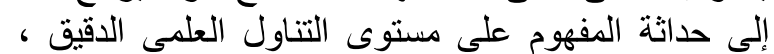

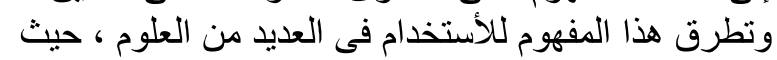

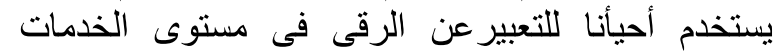

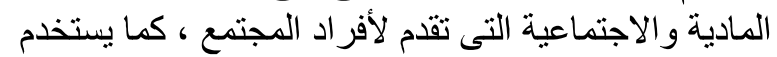

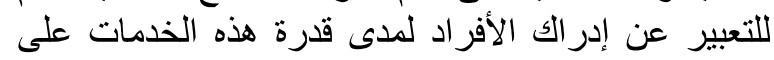

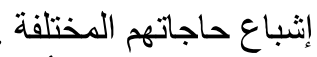

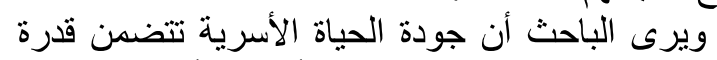

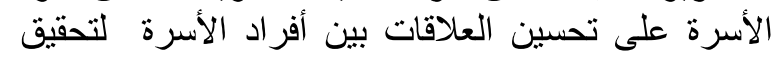

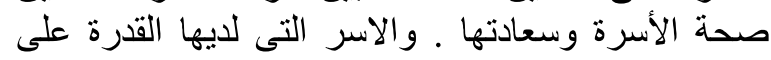

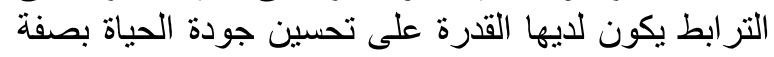
عامة. - مابط

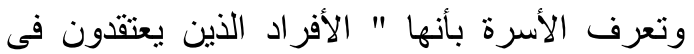

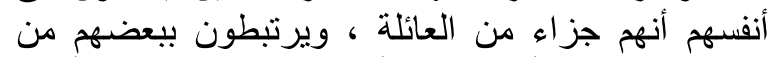

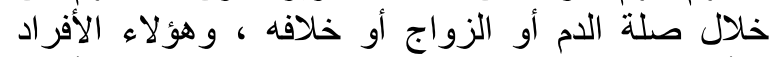

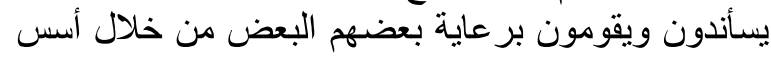

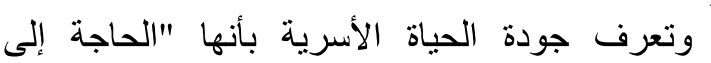

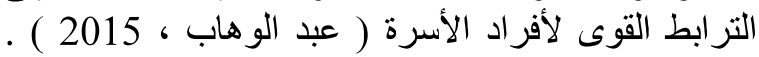

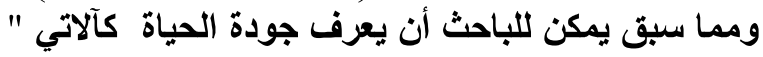

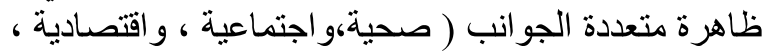

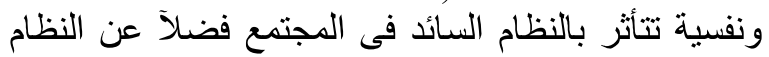

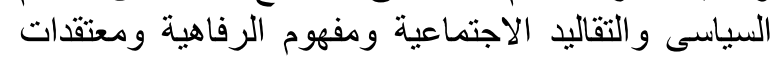

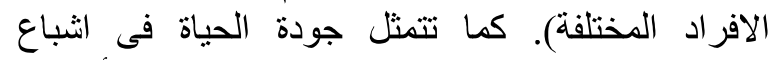

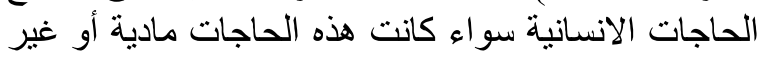

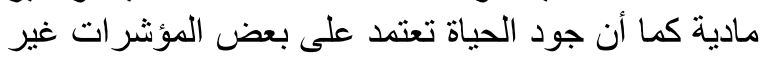

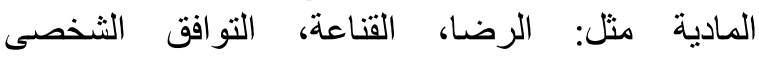

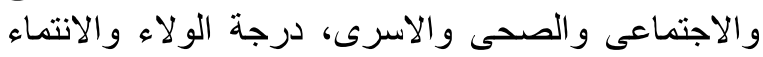

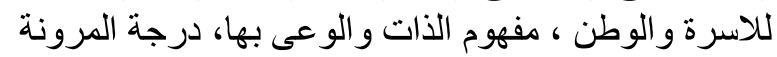
الفكرية وتقبل الاخر ( الثنقيرى ، الأنئ ، 2006).

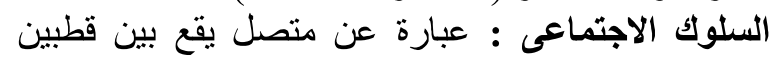

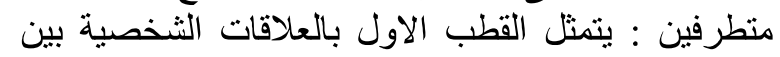

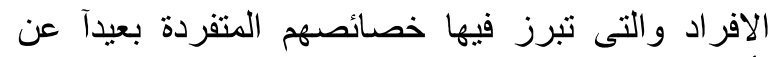

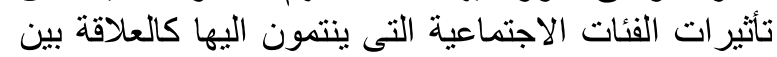

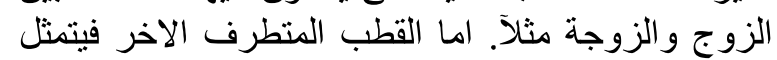

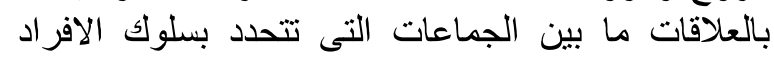

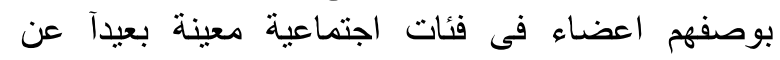

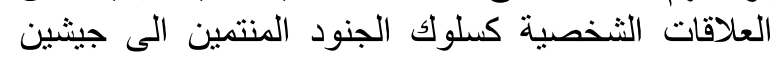
متقاتلين اثناء المعركة . (Tajfel and Turner,2004)
متميزة، وقدرات تكوينية مؤثرة، ومن ثم ما تحمله من وظائف اجتماعية فريدة.

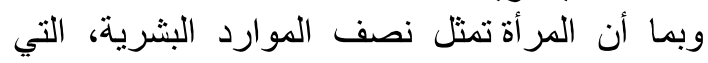

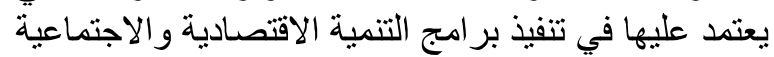

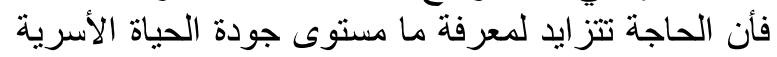

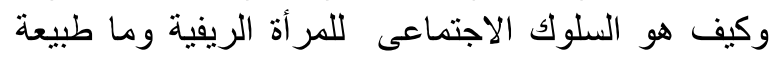

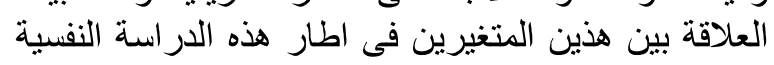
الاجتماعية لاى هذه الفئة .

1. 2. وفى ضوء العرض لاع العابق لمشُكلة البحث ، فأن التساؤل الرئيسى ل الهز البحث مؤداه ماهى العلاقة بين جودة البئماف العياة الأسرية والسلوك

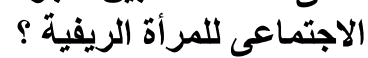

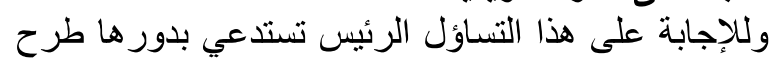

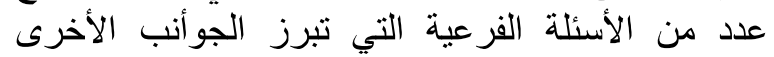

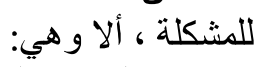

1-ما هى السمات ألثخصية اللثية للمر أة الريفية بعينة الدراسة ؟

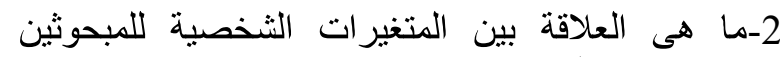
وجودة الحياة الأسرية ؟ العين 3-ما هى العلاقة بين المتغيرات الشخصية للمبحوثين والسلوك الاجتماعى ؟ أعلى 4-ما هى العلاقة بين جودة الحياة الأسرية والسلوك الاجتماعى للمبحوثين ؟ العافة

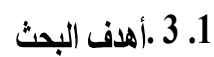

1- التعرف على التحث السمات الثخصية للمرأة الريفية بعينة الأسر اسة

2- التعرف على العلاقة بين المتغيرات الثخصية اللمبحوثين وجودة الحياة الأسرية

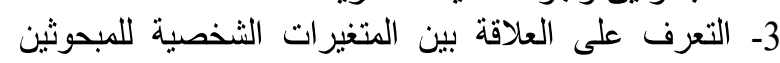
والسلوك الاجتماعى على العلافي

4- التعرف على العلاقة بين جودة الحياة الأسرية والسلوك الاجتماعى للمبحوثين 5-قياس جودة الحياة الأسرية للمر أة الريفية الرئية 6-قياس السلوك كان الاجتماعى للمر أة الريفية الرية

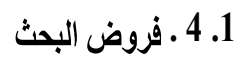

الفرض النظرى العام : " توجد علاقة بين جودة العباة العباة الأسرية

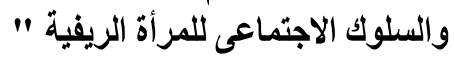

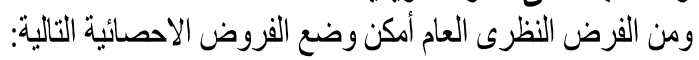

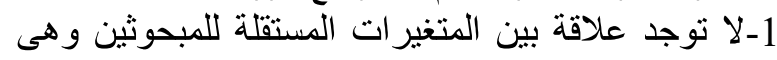

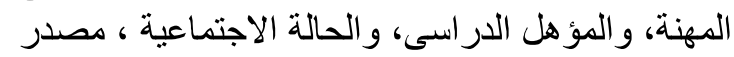

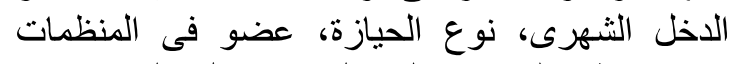

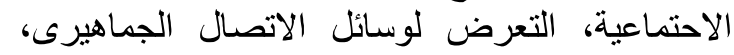

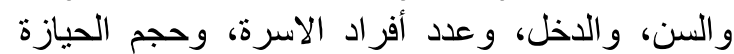

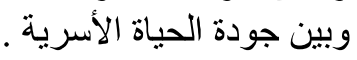

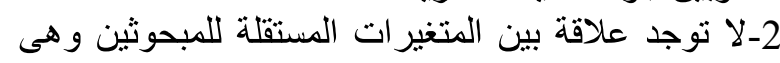

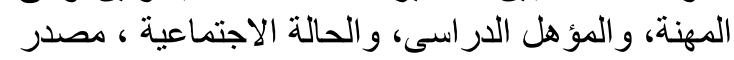

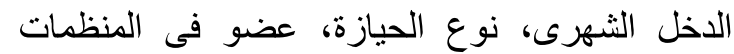
الاحتماعية، التعرض لوسائل الاتصال الجماهيرى، فئري، 


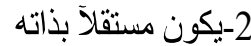

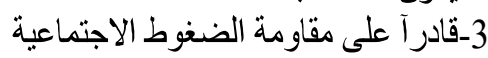

4-يتصرف بطر آنى منائق مناسبة

5-منظم فى سلوكه

6-يقيم ذاته بما يتناسب وقدل وقدر اته الشخصية

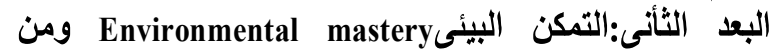
صفاته 1-الكفاية الذاتية للفرد

2-قدرة الفرد على التحكم و ادارة نشاطاته وبيئته 3-قدرته على الافادة من الفرص الفرد الفتاحة لديه

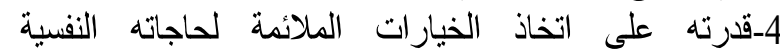
و الاجتماعية

5-قدرته على اختبار قيمة الثخصية

6-قدرته على التصرف على بما يتناسب مع معايير مجتمعه

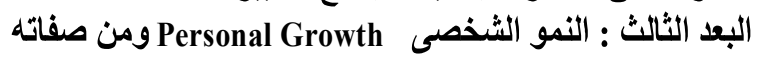

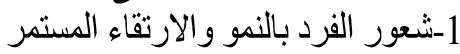

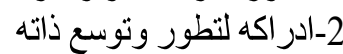

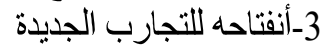

4-احساسه الو اقعى بالحياة

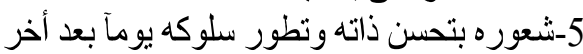

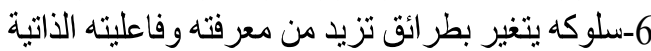

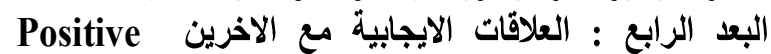

relation with others

1-رضا الفرد عن علاقاته الاجتماعية

2-تقته بالاخرين من حوله عن عله

3-قناعته بر فاهية الاخرين من حورين

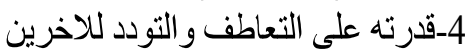

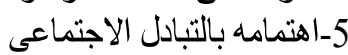

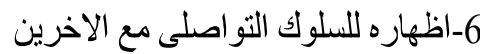

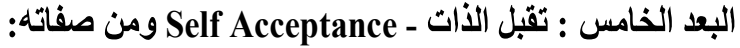

1-اظهار الفرد توجهاً ايجابياً نحو ذاته - الفاته

2-قبوله بالسمات أو الخصائص المكونة لذاته (السلبية و الايجابية )

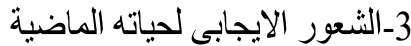

4-تفكيره الايجابى لذاته المستقبلية

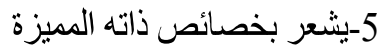

6-يظهز النقد الايجابى لذاته

البعد السادس : الهدف من الحياة Purpose in life ومن لإبه

صفاته

1-أن يمتلك المعتقدات التى تعطى معنى للحياة الماضيةو الحاضرة. 2-أن يضع اهدافآ تجعل حياته ذات معنى فى تحقئ تحقيقها. 3-أن يسعى لتحقيق غاياته فى الحياة . 4-أن تكون له القدرة على توجيه اهداف حياته

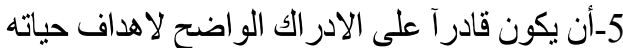

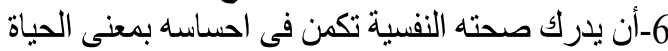
لقد بين (رايف) أن جودة حياة الفرد تكمن فى قدرته على مواجهة

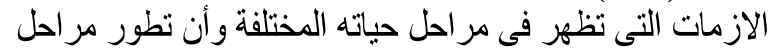

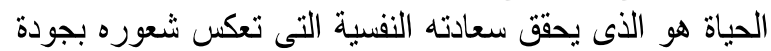
الحياة (Ryff,1989)

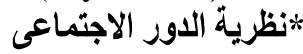

فى هذه النظرية اكد بارسونز (Parsons, 1966) على أن الن السلوك الاجتماعى للفرد يعتمد على طبيعة الادوار الوظيفية التى لئ
وقد بينت البحوث التى حلات عمليات التفاعل الاجتماعى اليومى وجود بعدين أساسيين هما بعد سلوك

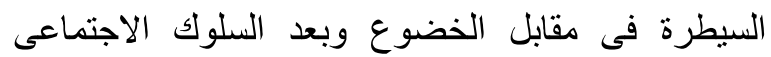

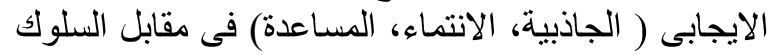
الاجتماعى السلبى (العدوان الذى يعد شكل من الأنى الشكال

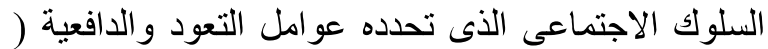

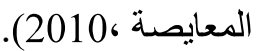

وعلى وفق نظرية التبادل الاجتماعى التى يتبناها

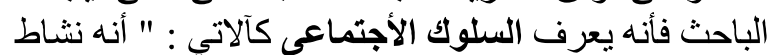

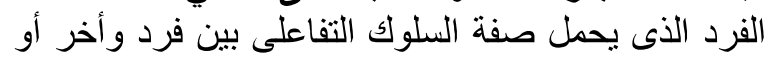

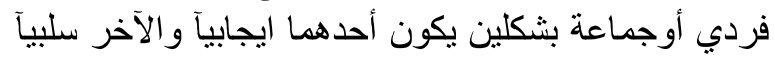

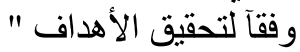

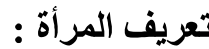

ماذا تعنى لنا كلمة أمرأة لأول وهلة نسمع فيه هذا

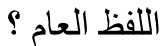

عندما تتحدث عن المرأة يخطر لنا عادة معنيأن متر ادفأن

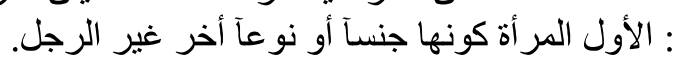
1. 6 ـ الموجهات النظرية للاراسة المونة ويرى الباحث أن جودة الحياة هى العلاقة بين الفرد وبيئته

فضلآ عن ذلك فأن التوجهات النظرية الحديثة قد أكدت فى هئه

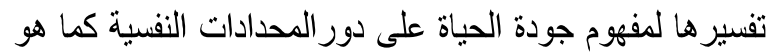

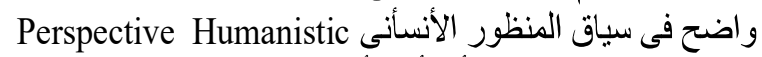
حيث يرى المنظور الأنسأنى أن فكرة جودة الحئئن الحياة تستلزم

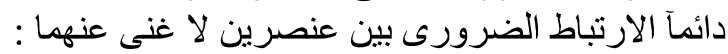
- وجود كائن حى ملائم - وجود بيئة جيدة يعيش فيها هذان هذا الكائن ذلك لأن ظاهرة الحياة

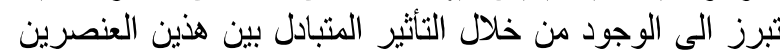

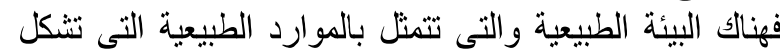

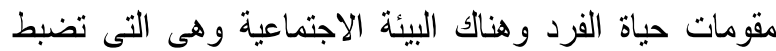

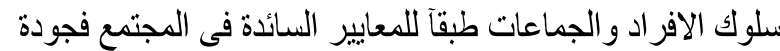

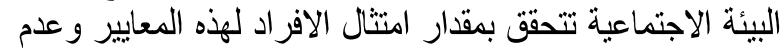

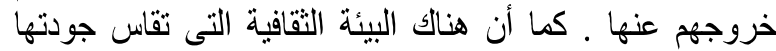

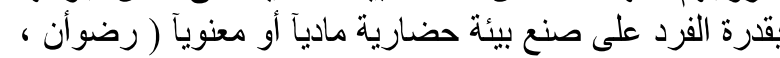
. 2006

لقد اكد هذا المنظور فى تفسيره لجودة الحياة على مفهوم الذات Self Concept وقد بين أن حقيقة الحياة الأنسأنية تنطوى هلئي مفود

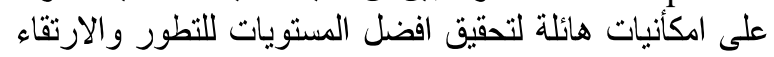

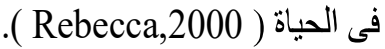
ومن أكثر النظريات حداثة ضمن هذا المنظور

ـ نظرية رايف ( Ryff Theory,1999)

تدور حول مفهوم السعادة النفسية Psychological happiness

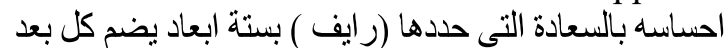

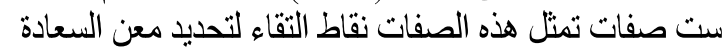

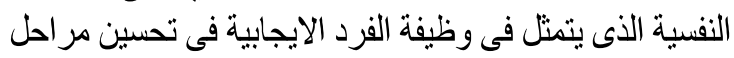
البعد الاوله وهذه الابعاد هى : الاستقلاية Autonomy وصفاته تثمثل بقدر الثخص على أن الن الأن 1-يقرر مصيره بنفسه ان علئ 
ولا نوجد فروق فى درجة الثعور بجودة الحباة بين الذكور

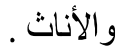

2 الإجراءات المنهبية للاراسة نوع الاراسة والمنهج المستخدم

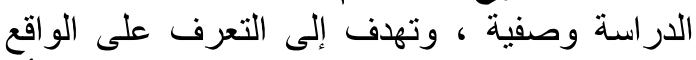

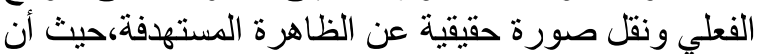

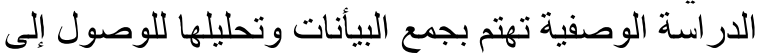
نتائج يمكن تعميمها. وفي هذا البحث أستخدم المنهج الوصفي الذي يعتبر

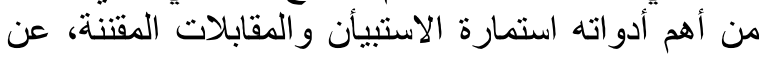

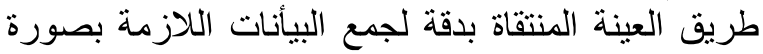

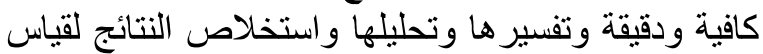

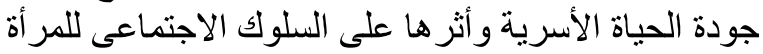

$$
\text { الريفية بالمجتمعات الصحر الداوية الداتية }
$$

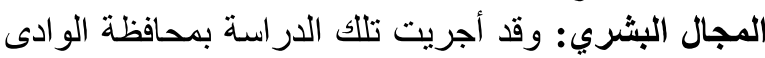

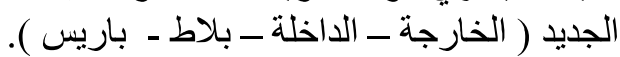

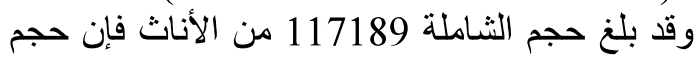
العينة 384 مبحوثآ وفقآ للجدول مورجأن لتحديد حجم العان

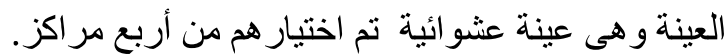

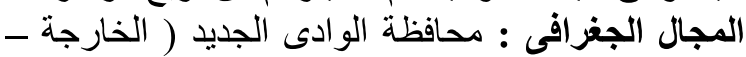

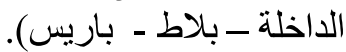

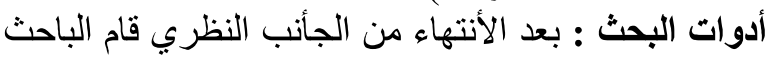

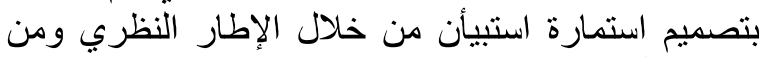

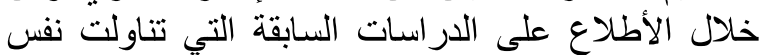

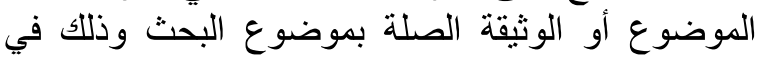

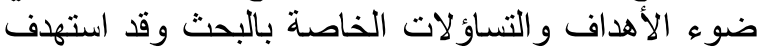
الباحث من خلال إستمارة الاستبيان الحصول على الفى بياندات متعلقة بموضوع البحث وفقاً لأهداف البحث الحان الحالية

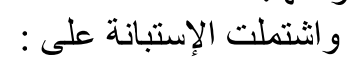

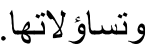

مقدمة توضح الهدف من إجراء الاستبائنة وطريقة الاستجابة عليها و البيانات الأساسية

قياس لجودة الحياة الأسرية للمرأة الريفية (عبدانية

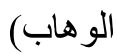

قياس للسلوك الاجتماعى للمر أة الريفية (مبارك) وتم جمع البيأنات بالمقابلة الثخصية للباحث لإن مع المبحوثين

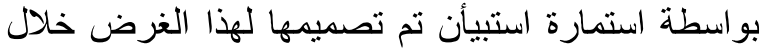
شهر يناير وفبرير 2020 . المعالجة الكمية للبيأنات

بعد الإنتهاء من جمع البيانات على النحو السابق تم

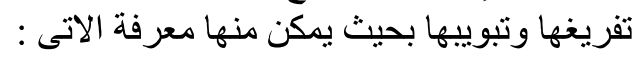

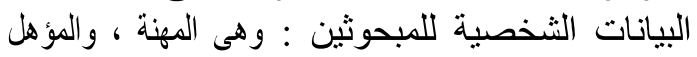

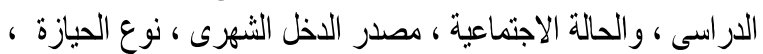

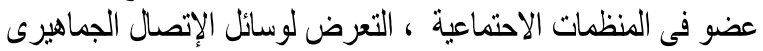

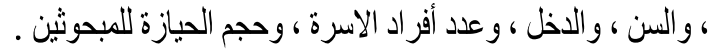

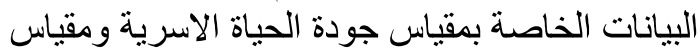

السلوك الاجتماعى للمر أة الريفية :

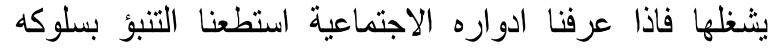

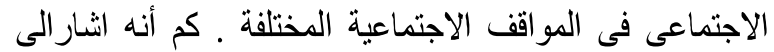

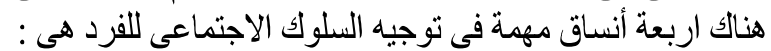

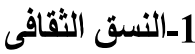

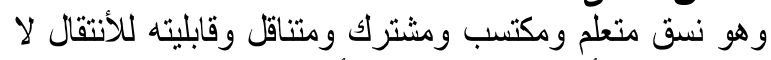

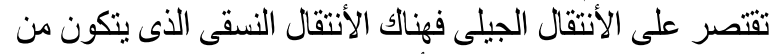
التقاليد و القيم والمعايير والقو أنيين ووسائل الاتصال التئل التى تكسبه

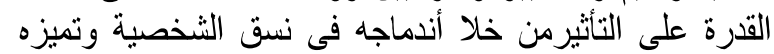

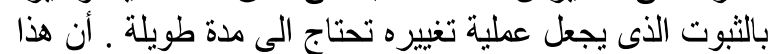

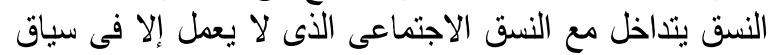
التراث النقافي

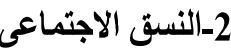

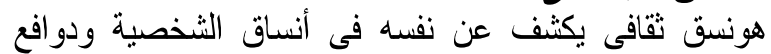
الافر اد عندما يلتقون فى موقف اجتماعى محدد.

3نست الثخصية

وهو مظهر الفرد كونه ممثل اذ أنه يكون مفهوماً للأنماط

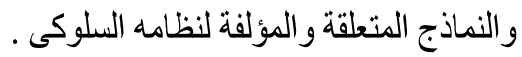

وهو يثنير اللى النظام السلوكى بوظائفه المعرفية والتكيفية 4-الكائن السلوكى النعل المختلفة (حسين ، 2005).

وقد بين سملسر ( Smelser,1970) أن هذه الأنساق تعمل على توجيه السلوك الاجتماعى نحو غاية أو هدف محدد وأن أن القين القيم

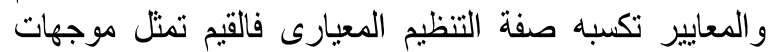
السلوك الاجنماعى اما المعايير فهى الضوابط الطئ المحددة له ه.

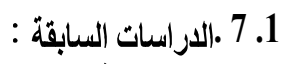

توصلت إدراسة 1993, Merrell لى لى أن هناك علاقة ايجابية

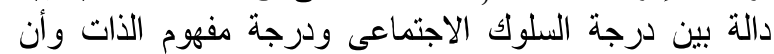

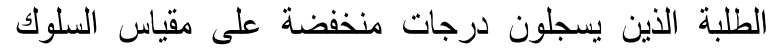

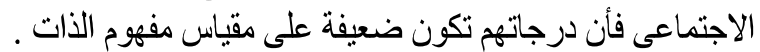
اشنارت دراسة Kinner et al.,1994 الى أن هناك على علاقة دالة

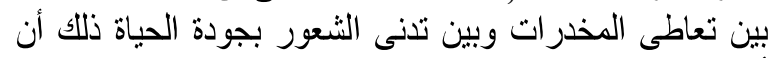

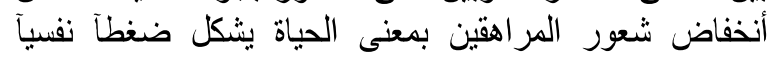

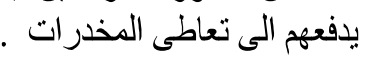

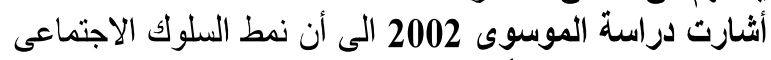

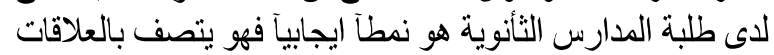

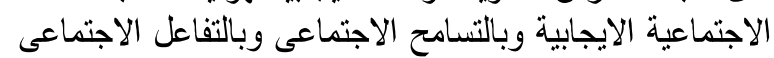

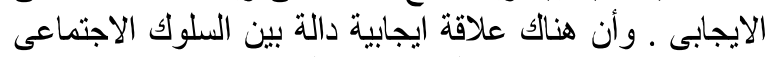
والشعور بالامن النفسى وأن العلاقة كأنت غير دالة بين بين السلوك الإلى

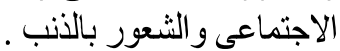

توصلت دراسة Baptista et al.,2006 الى أن هناك علاقة دالة بين كل من الصحة النفسية وجودة الحياة وأن متغيرات النيات

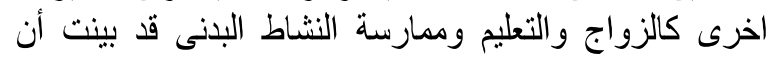

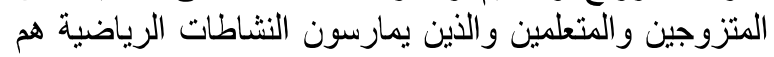

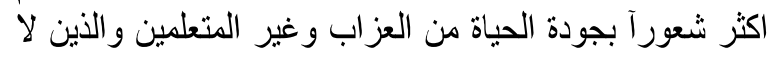
يمارسون النشاطات الرياضية ل بينت دراسة الجميل 2008 أن طلبة الجامعة يتمتعون بجودة الجياض

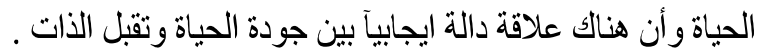

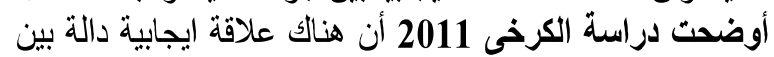
جودة الحياة والذكاء الأنفعالى ولاى عينة من المرشدين التربوين 
وبلغت نسبته 37.0\% ، يليها المبحوثين التى تتراوح اعمار هم ما بين

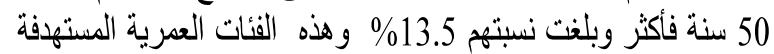

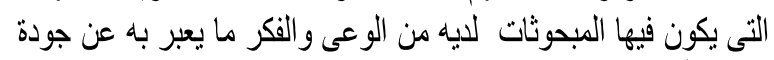

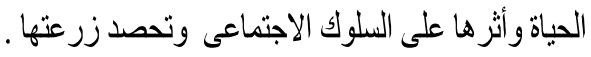

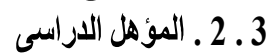

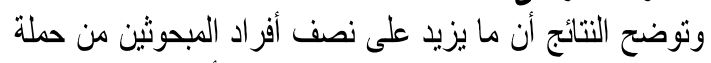

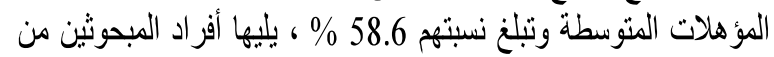

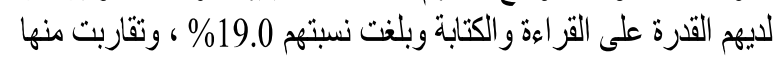

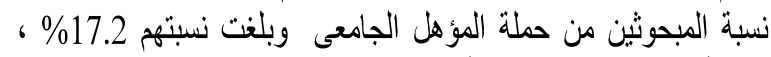

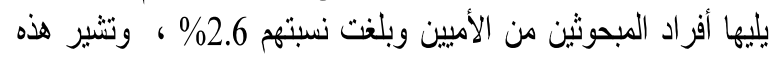

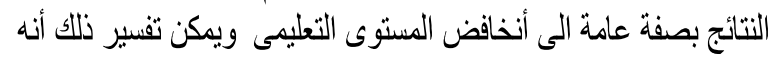

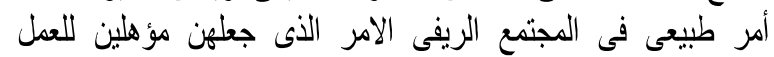

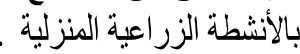
3. 3

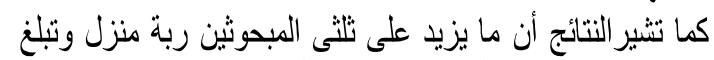

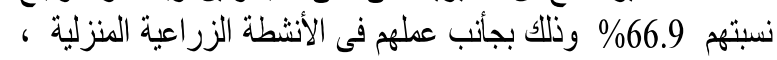

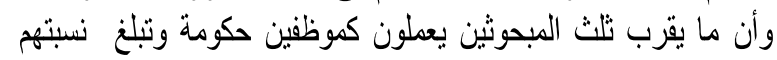

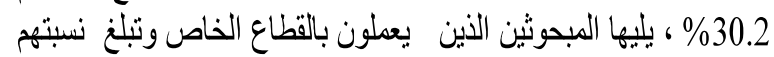

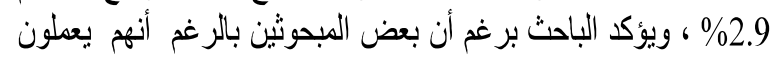

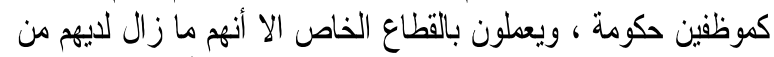

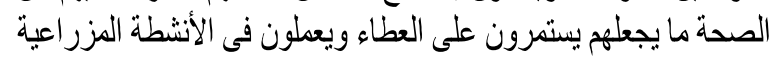

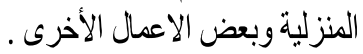

(الحالة الاجتماعية الاعرية

وتوضح النتائج أن مايزيد على ثلثى المبحوثين متزوجين وتبلغ

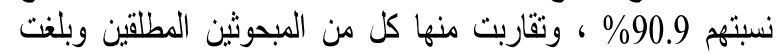

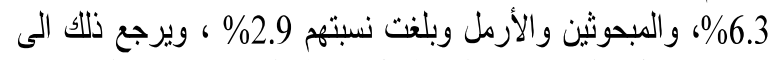

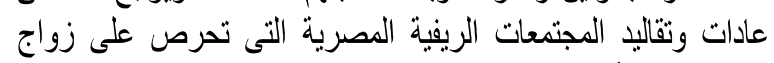
الابناء مبكر آلأنه عفة وحماية للثنباب .

5 3 ـ علد أفراد الأسرة

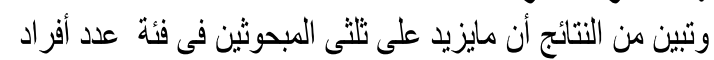

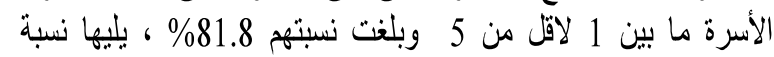

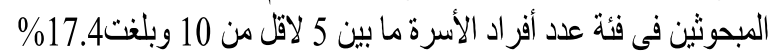

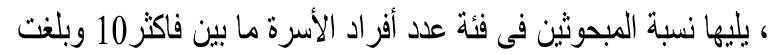

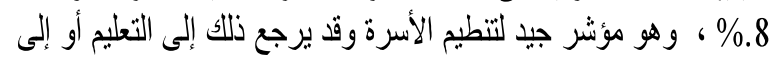

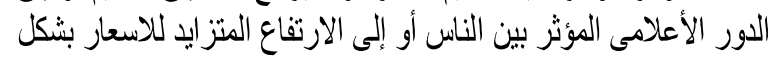

$$
\text { مخيف وصعوبة الحياة . }
$$$$
\text { 6 } 6 \text { ـ الاخل الثهرى }
$$

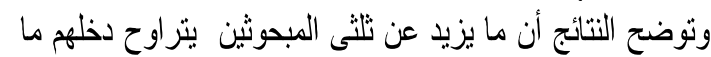

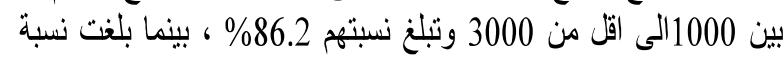

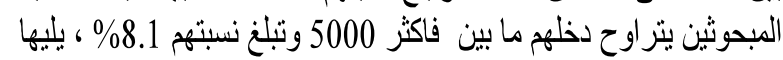

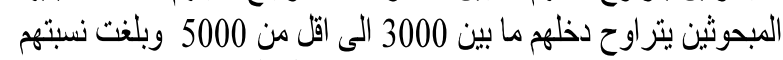

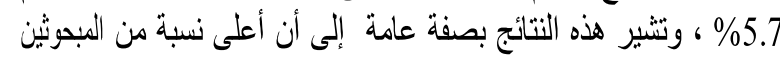

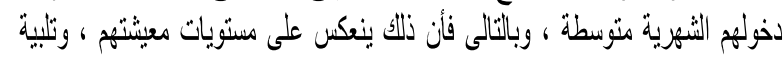

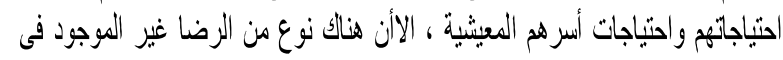

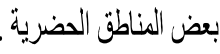

لمعرفة جودة الحياة الاسرية فقد تضمن استمارة

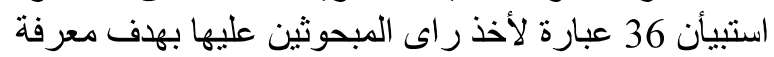

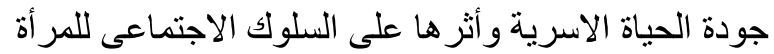

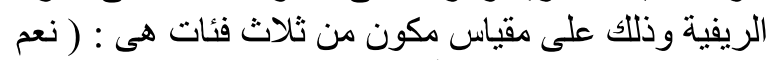

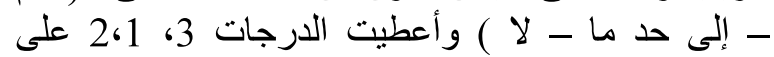

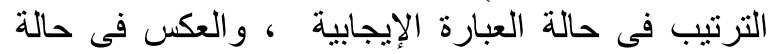

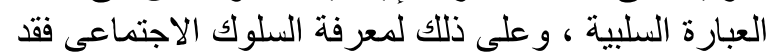

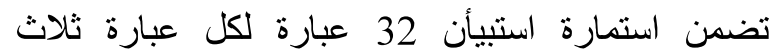

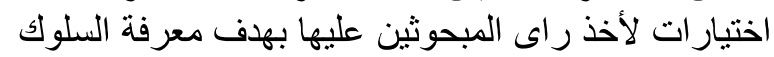

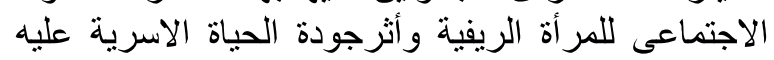

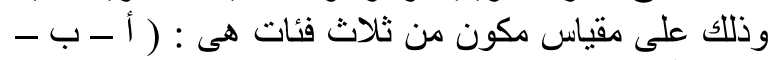

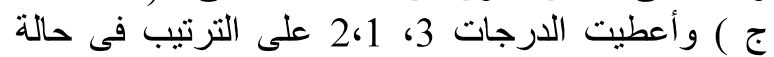

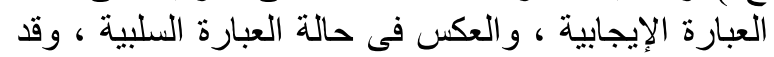

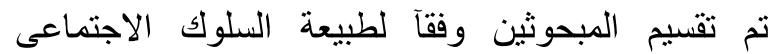

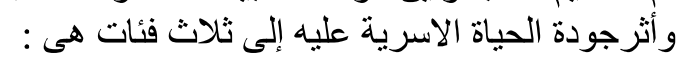

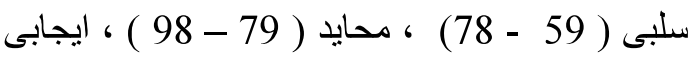

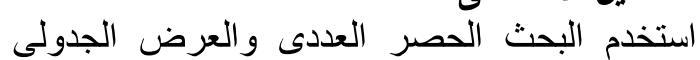

بالتكر ار و النسب المئوية لعرض البيانيات الثخدصية لعينة

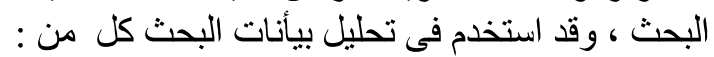

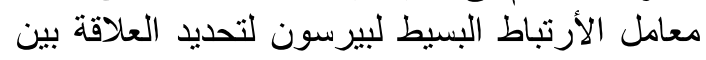

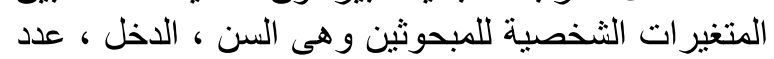

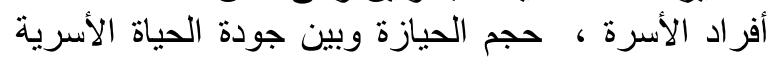

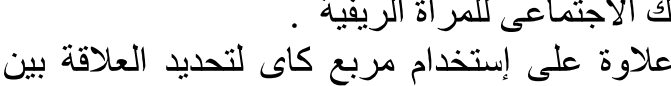
بعض المتغير ات الثخصية للمبحوثين.

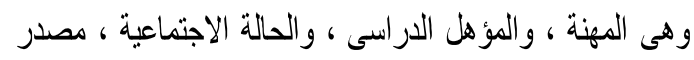

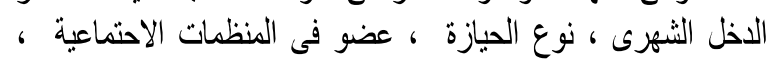

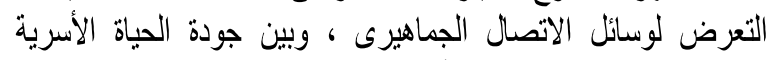

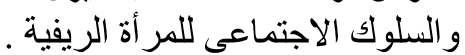

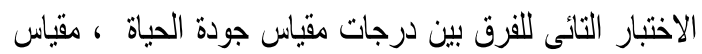

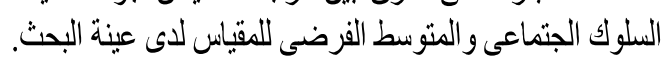

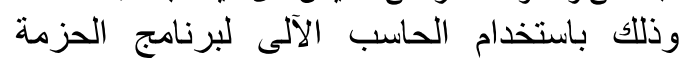
الإحصائية للعلوم الإجتماعية بائمانية

\section{3. - النتائج ومناقتشها}

نتناول وصفاً لعينة البحث من حيث الخصائص التالية المدروسة

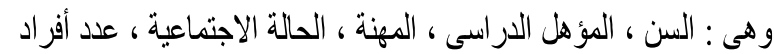

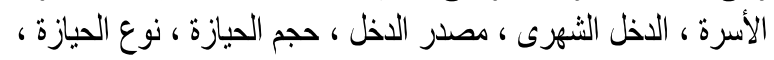
عضو فى اية من المنظمات الآتية ، التعرض لونئل لوسائل الاتصال

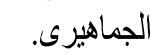
( السن 1 ـ السن

كما تتثير النتائج أن ما يقرب من نصف المبحوثين نتراوح نسبة

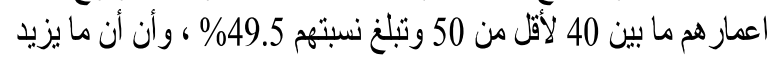
على ثلثى أفر اد المبحوثين تتز اوح نسبة اعمار هم ما بين 30 لاقل من 40.50 
جدول (1): توزيع المبحوثين وفقاً لمتغيراتهم الشخصية.

\begin{tabular}{|c|c|c|c|c|c|}
\hline$\%$ & العدد & المتغيرات الشخصية & $\%$ & العدد & المتغيرات الشخصية \\
\hline \begin{tabular}{c|}
66.1 \\
16.4 \\
11.5 \\
6.6 \\
100
\end{tabular} & $\begin{array}{c}254 \\
63 \\
44 \\
23 \\
384\end{array}$ & أرضب شهر الاخل الشهرى & $\begin{array}{l}37.0 \\
49.5 \\
13.5 \\
100\end{array}$ & $\begin{array}{c}142 \\
190 \\
52 \\
384\end{array}$ & 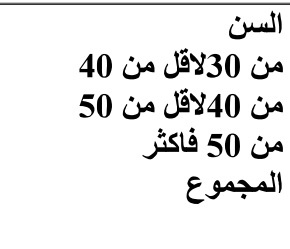 \\
\hline $\begin{array}{r}91.9 \\
8.1 \\
0 \\
100\end{array}$ & $\begin{array}{r}353 \\
31 \\
0 \\
384\end{array}$ & 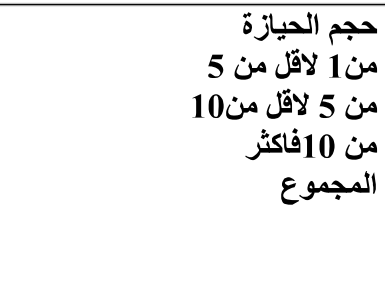 & $\begin{array}{c}2.6 \\
19.0 \\
58.6 \\
17.2 \\
2.6 \\
100\end{array}$ & $\begin{array}{c}10 \\
73 \\
225 \\
66 \\
10 \\
384\end{array}$ & 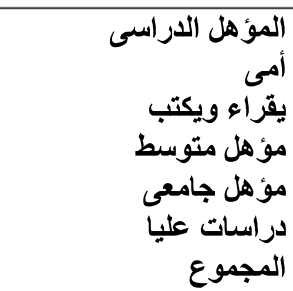 \\
\hline $\begin{array}{l}47.1 \\
41.9 \\
10.9 \\
100\end{array}$ & $\begin{array}{c}181 \\
161 \\
42 \\
384\end{array}$ & ملوع الحيازة & $\begin{array}{c}30.2 \\
66.9 \\
2.9 \\
100\end{array}$ & $\begin{array}{c}116 \\
257 \\
11 \\
384\end{array}$ & 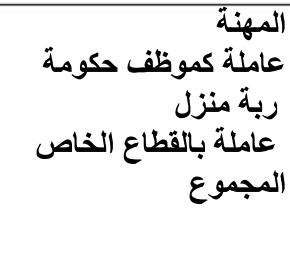 \\
\hline $\begin{array}{c}72.1 \\
27.9 \\
0 \\
0 \\
100\end{array}$ & $\begin{array}{c}277 \\
107 \\
0 \\
\mathbf{0} \\
\mathbf{3 8 4}\end{array}$ & 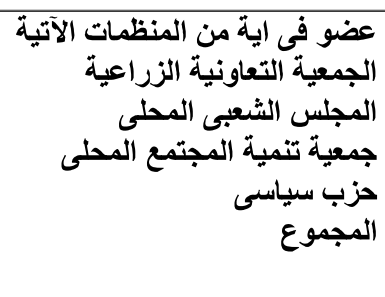 & $\begin{array}{c}90.9 \\
6.3 \\
2.9 \\
0 \\
100\end{array}$ & $\begin{array}{c}349 \\
24 \\
11 \\
0 \\
384\end{array}$ & المتزوج المالة الاجتماعية \\
\hline $\begin{array}{r}5.7 \\
5.7 \\
56.5 \\
32.0 \\
100\end{array}$ & $\begin{array}{r}22 \\
22 \\
217 \\
123 \\
384\end{array}$ & 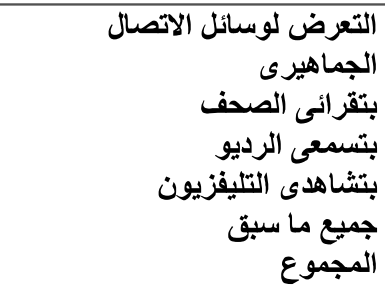 & $\begin{array}{c}81.8 \\
17.4 \\
8 \\
100\end{array}$ & $\begin{array}{c}314 \\
67 \\
3 \\
384\end{array}$ & من مند الفراد الاسرة 5 لاقل من 5 من من 10 مناكثر 10 \\
\hline & & & $\begin{array}{r}86.2 \\
5.7 \\
8.1 \\
100\end{array}$ & $\begin{array}{r}331 \\
22 \\
31 \\
384\end{array}$ & 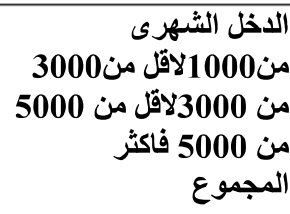 \\
\hline
\end{tabular}


على أنفسه من الوقوع فى المعصية حيث تثميز المجتمعات الريفية

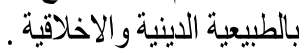

جدول (2): طبيعة شعور المبحوثين نحو مقياس جودة الحياة الأسرية

\begin{tabular}{|c|c|c|}
\hline$\%$ & 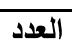 & طييعة الشعور بجودة الحياة الأسرية \\
\hline 9.1 & 35 & لا يشعرون بجودة الحياة الأسرية (72- 84) \\
\hline 25.8 & 99 & الى حد ما يشعرون بجودة الحياة الأسرية (85- 97) \\
\hline 65.1 & 250 & نعم يشعرون بجودة الحياة الأسرية (98- 110) \\
\hline 100 & 384 & المجموع \\
\hline
\end{tabular}

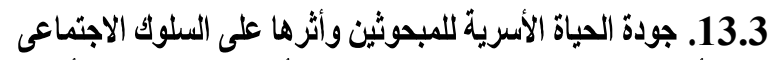

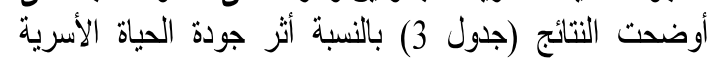

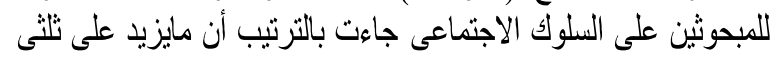

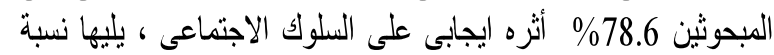

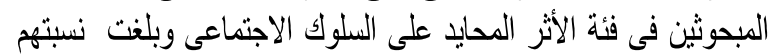
18.5

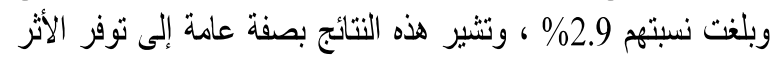

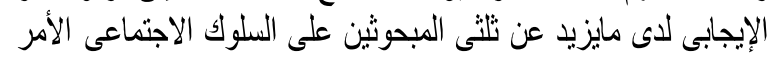

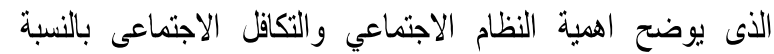

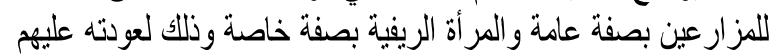

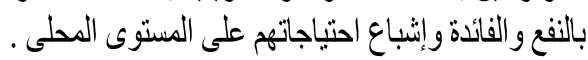

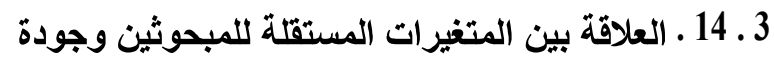
الحياة الأسرية المئة المغير

ينص الفزض الاحصائى الأول على أنه " لا توجد علاقة بين

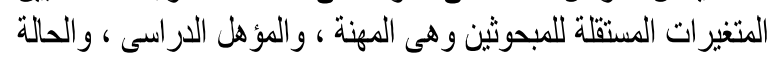

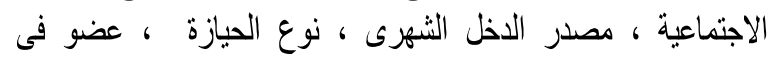

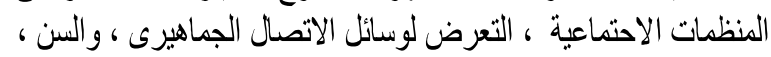

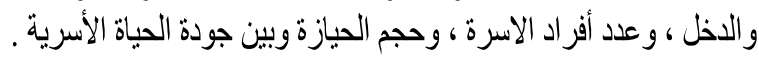

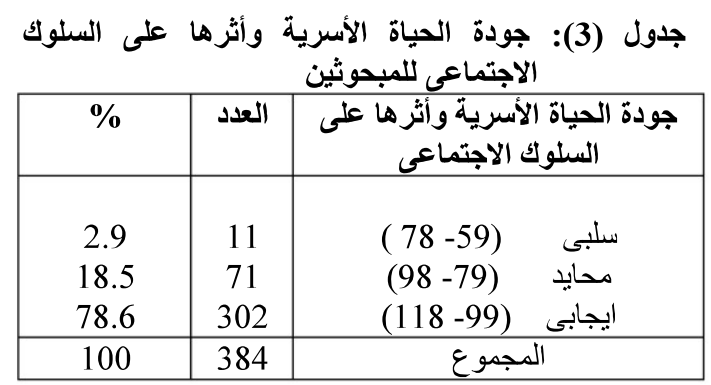

\section{نتائج اختبار مريع كاى}

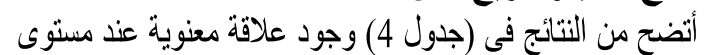

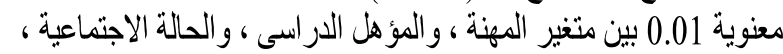

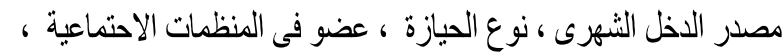

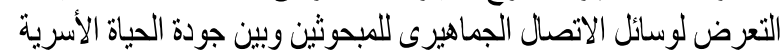

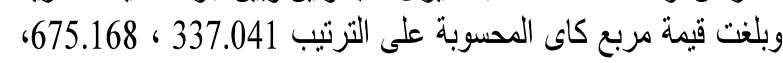

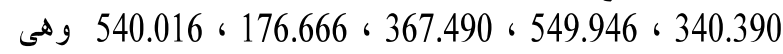

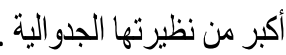

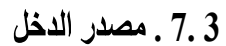

كما تشثير النتائج أن ما يزيد على تلثى المبحوثين المشتركين

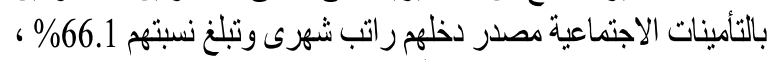

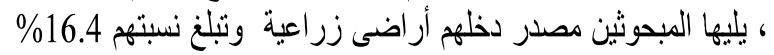

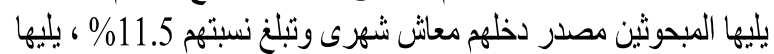

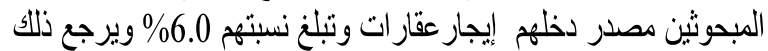
إلى أن معظم أفراد العينة يعملون بالحكومة مقابل أجر شهرى بجأنب

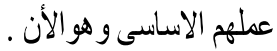
8.3

وتوضح النتائج أن ما يزيد على ثلثى المبحوثين حجم الحيازة

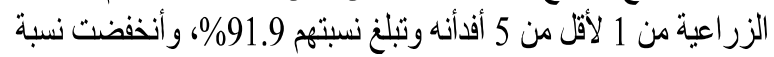

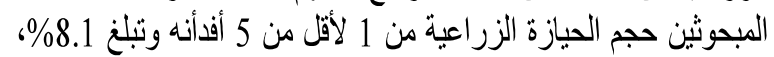

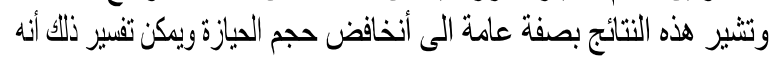

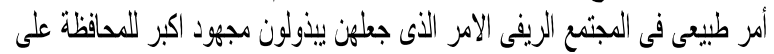
أنتاجية الفأن .

9.3 وتبين النتائج أن ما يقرب نصف المبحوثين نوع الحيازة الزراعية

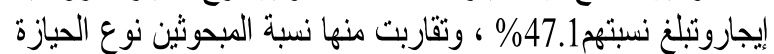

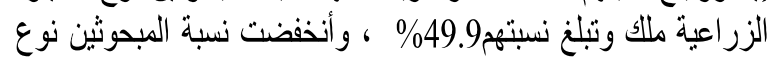

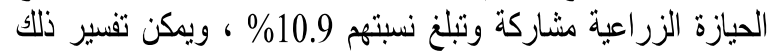
بأنفاض مستوى المعيشة فى المجتمع الريفى ـ الزئن

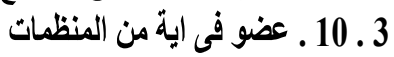

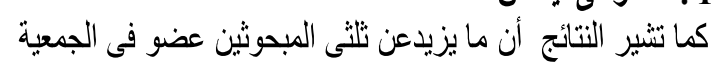

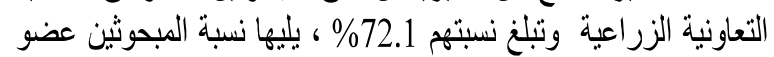

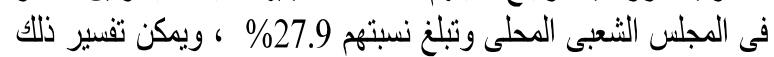

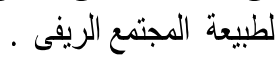

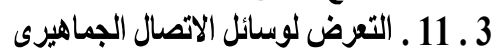

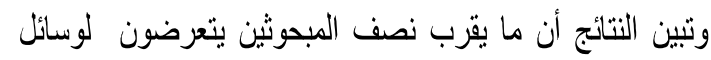

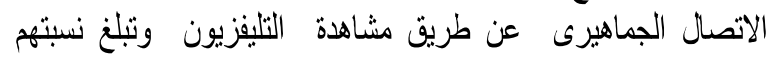

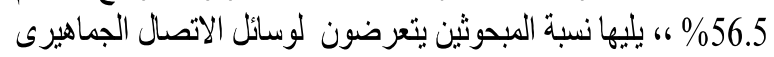

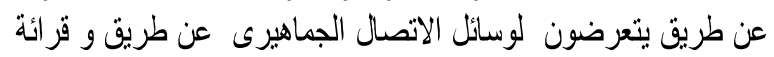

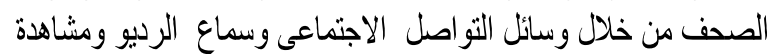

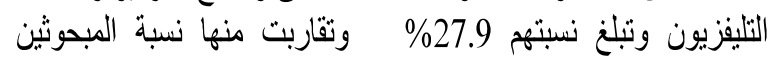

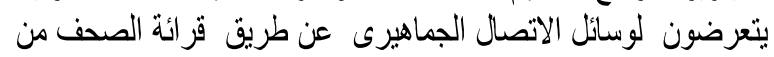

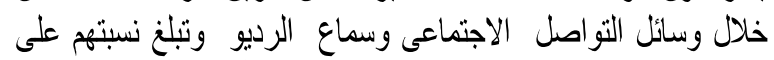

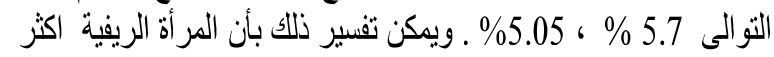

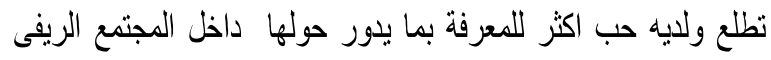

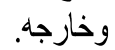

3 ـ 12 ـ طبيعة شعور المبحوثين نحو مقياس جودة الحياة

$$
\text { الأسرية }
$$

أوضحت النتائج (جدول 2) بالنسبة طبيعة شعور المبحوثين نحو

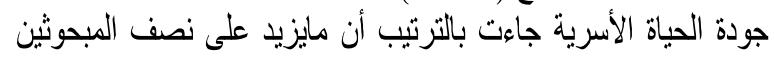

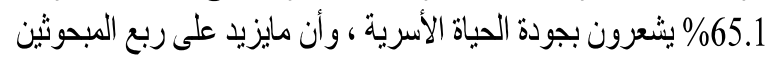

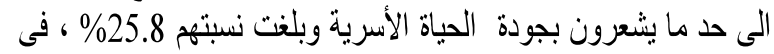

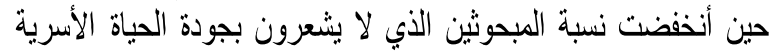

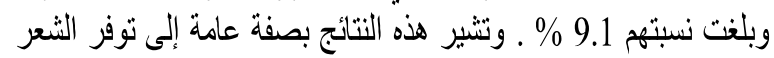

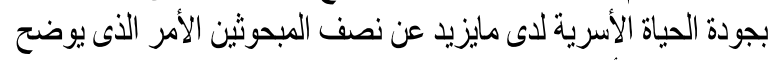

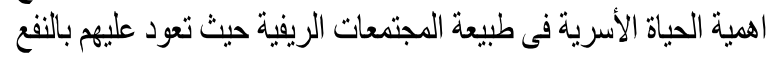

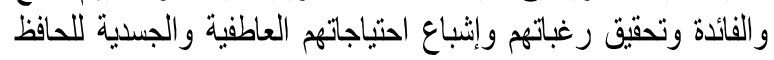


تفسير العلاقة بين المؤهل الدراسى للمبحوثين وبين جودة الحياة الأسرية

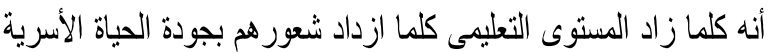

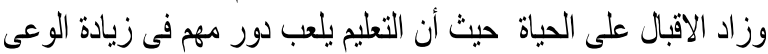

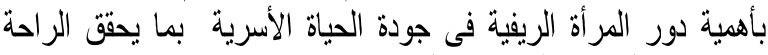

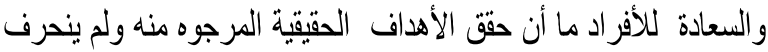

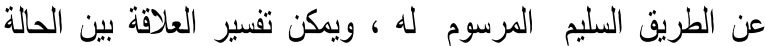

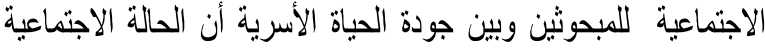

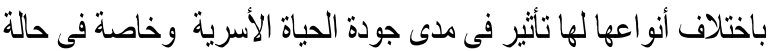

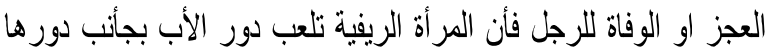

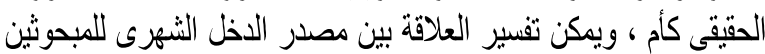

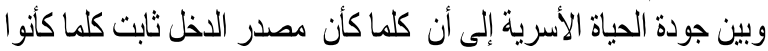

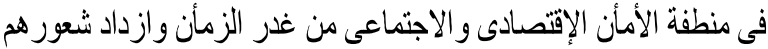

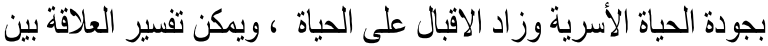

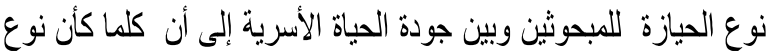

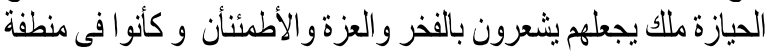
الأمأن الإقتصادى والاجتماعى وازداد شعور هم بجودة بلإدة الحياة الأسرية

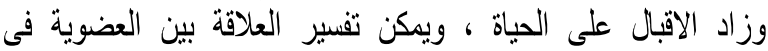

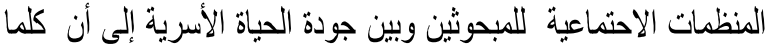

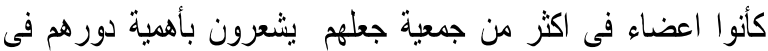

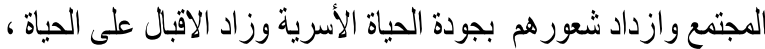

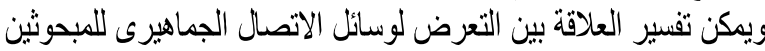

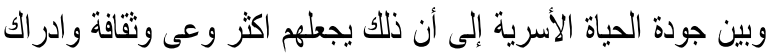

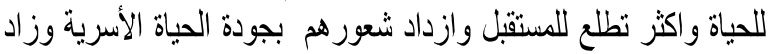

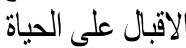

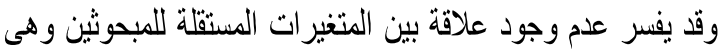

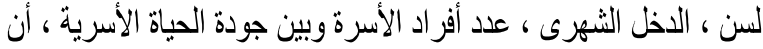

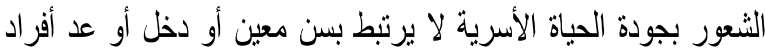

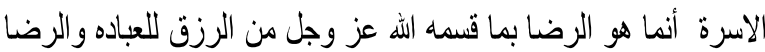

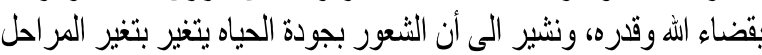

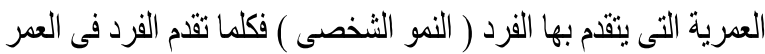

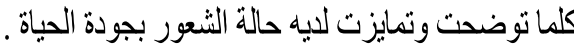

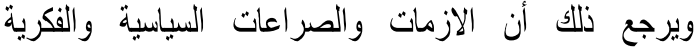
والاقتصادية التى مر بها المجتمع المصرى خلال السنو ات السابقة لم تكن

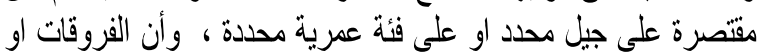

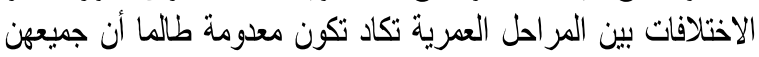

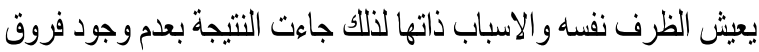

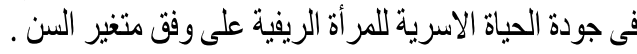

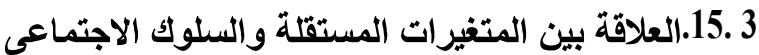
للمبحوثين

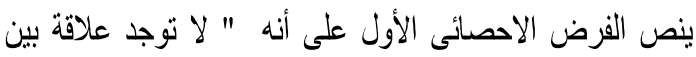

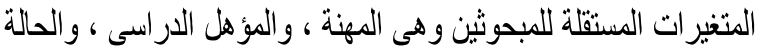

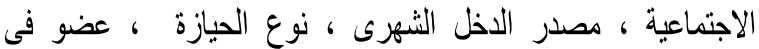

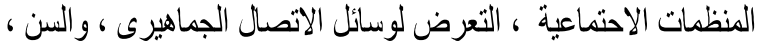

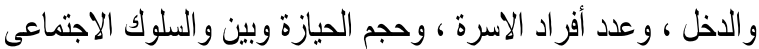

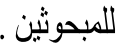
ت-نتائج اختبار مريع كاى

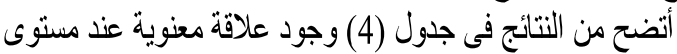
معنوية 0.01 بين متغير المهنة ، والمؤهل الدراسى ، والحالة الاجتماعية،
جدول(4):العلاقة بين المتغيرات المستقلة للمبحوثين وجودة الحياة الأسرية.

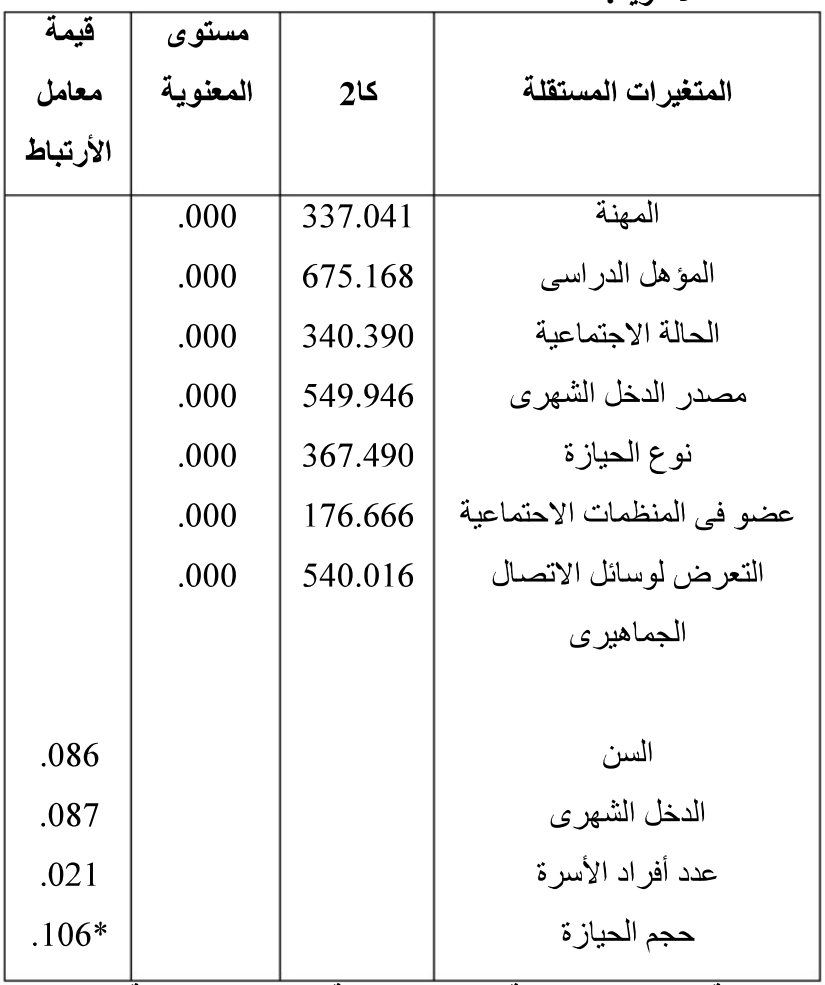

* * معنوية عند مستوى معنوية 01 , معنوية عند مستوى معنوية 05,

\section{بنتائج أختبار معامل الارتباط البسيط}

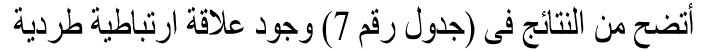

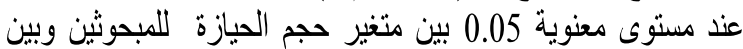

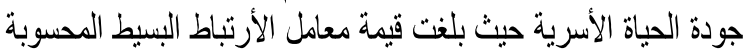

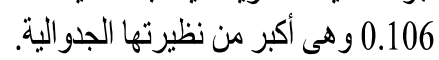

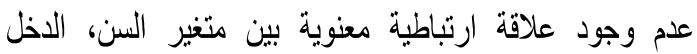

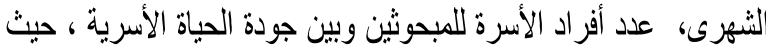

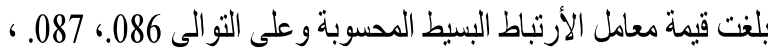
021 و هى أقل من نظيرتها الجدو الية .

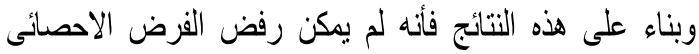

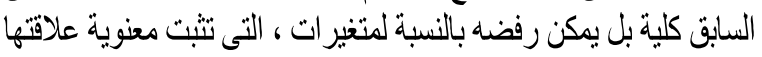

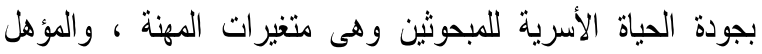

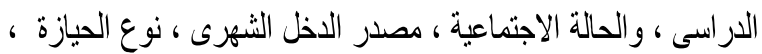

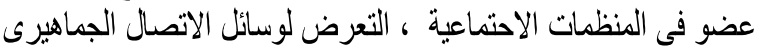

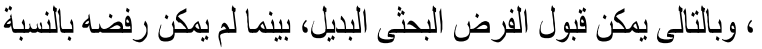
لباقى المتغير ات الستقلة وهى السن ، الدخل الشهرى ، عدد ألفراد الأسرة

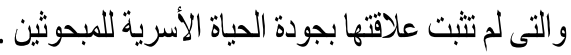

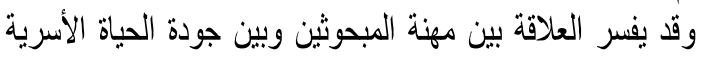

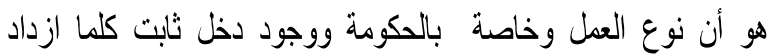

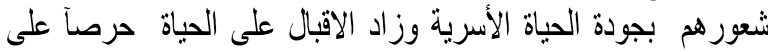

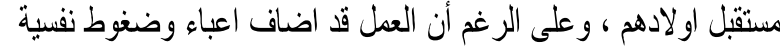

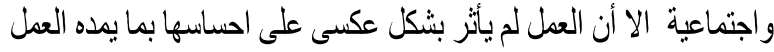

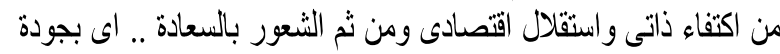

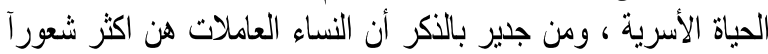
بجودة الحياة الأسرية من اقر أنهن غير العاملات Perry, 1994 كويككن العناء 


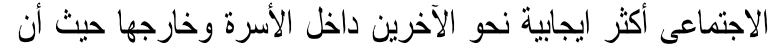

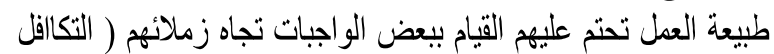

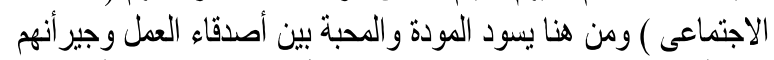

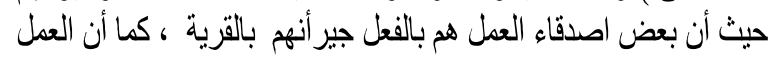

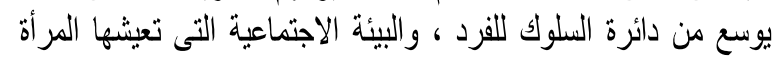

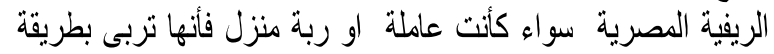

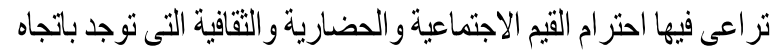

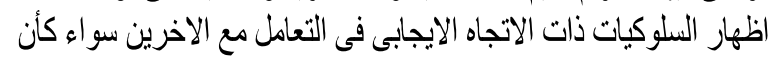

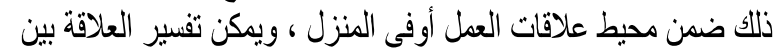

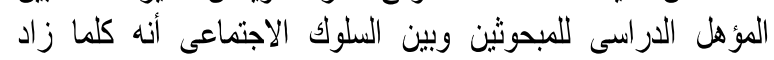

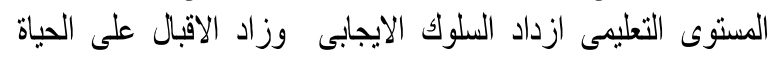

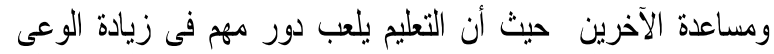

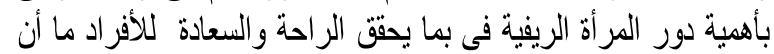

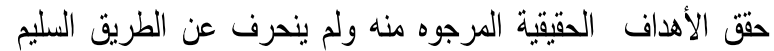

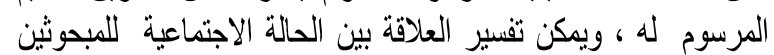

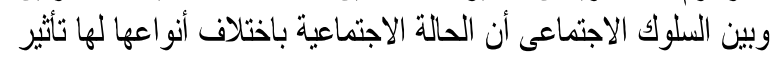

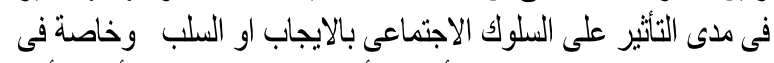

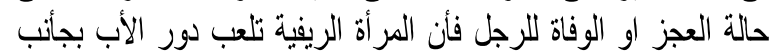

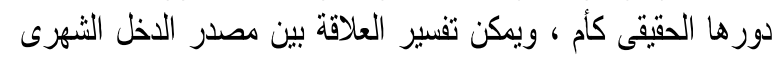

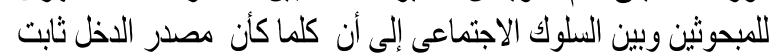

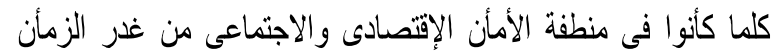

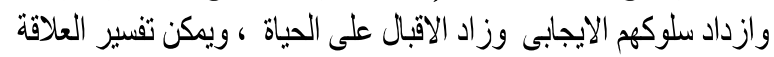

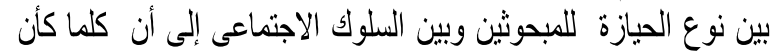

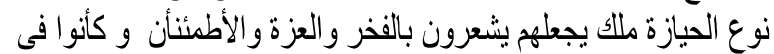

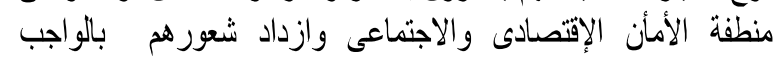

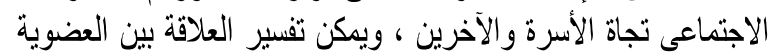

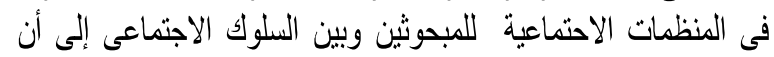

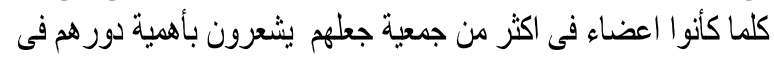
المجتمع وازداد شعور هم ب بالو اجب الاجتماعى فى مساعدة اهل لهن القرية
مصدر الاذل الثهرى ، نوع الحيازة ، عضو فى المنظمات الاحتماعية،

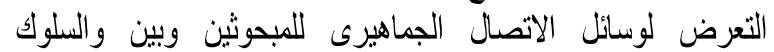

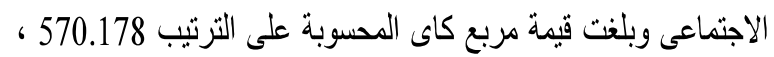
، 603.108 616.243 وهى أكبر من نظيرتها الجدو الية. ثنتائج أختبار معامل الارتباط البسيط لنيط

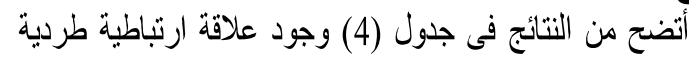

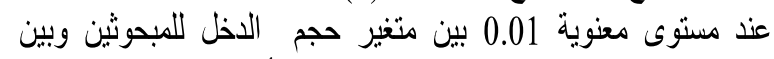

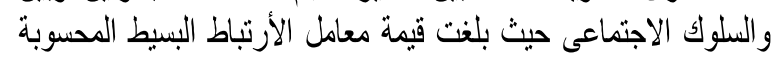

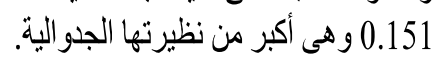
وجود علاقة ارتباطية طردية عند مستوى معنوية 0.15 ودية 0.05 بين متغير السن للمبحوثين وبين و السلوك الاجتماعى حيث بلغت قيت قيمة معامل الأرتباط

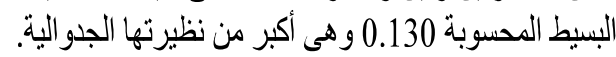

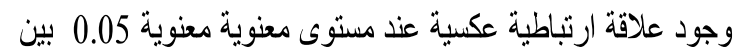
متغير حجم الحيازة للمبحوثين وبين والسلوك حيث بلثئ بلغت قيمة معامل

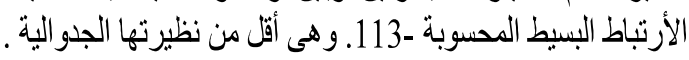
عدم وجود علاقة ارتباطية معنوية بين متغير عدد أفراد الأسرة

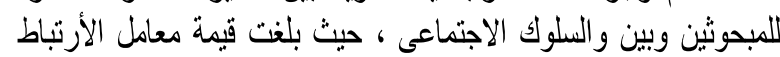
البسيط المحسوبة 035.

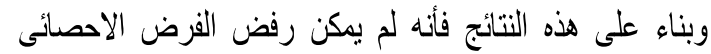

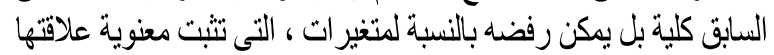

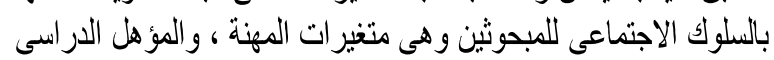

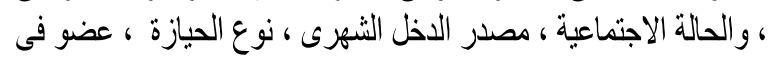

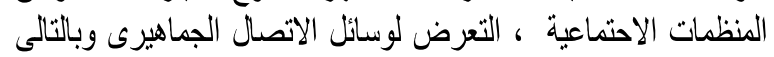

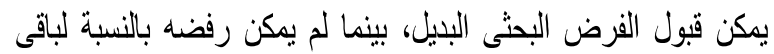

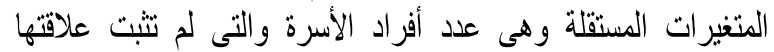

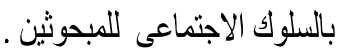

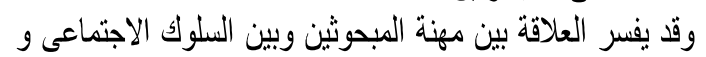

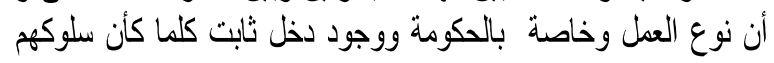

جدول (5): العلاقة بين المتغيرات المستقلة والسلوك الاجتماعى للمبحوثين

\begin{tabular}{|c|c|c|c|}
\hline قيمة معامل الأرتباط & مستوى المعنوية & 25 & المتفيرات المستقلة \\
\hline & .000 & 570.178 & المهنة \\
\hline & .000 & 603.108 & المؤهل الدراسى \\
\hline & .000 & 632.824 & الحالة الاجتماعية \\
\hline & .000 & 832.505 & مصدر الدخل الثهرى \\
\hline & .000 & 343.316 & نوع الحيازة \\
\hline & .000 & 199.151 & عضو فى المنظمات الاحتماعية \\
\hline & .000 & 616.243 & التعرض لوسائل الاتصال الجماهيرى \\
\hline $130 .^{*}$ & & & السن \\
\hline .035 & & & عدد أفراد الأسرة \\
\hline $.151^{* *}$ & & & الدخل الشهرى \\
\hline $.113 *_{-}$ & & & حجم الحيازة \\
\hline
\end{tabular}


هذا المتوسط بالمتوسط الفرضى للمقياس وهو 0.502 درجة يلاحظ أنه أكبر من المتوسظ الفرضى الفرضى للمقياس ولدى

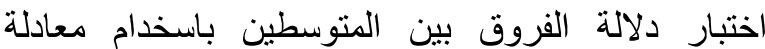

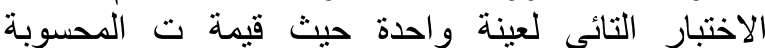

169.431، تبين أنه دال معنوياً عند مستوى دلالة 0.01

جدول ( 6 ) : الاختبار التائى للفرق بين درجات مقياس جودة الحياة و المتوسط الفرضى اللمقياس لإى عينة البحث.

\begin{tabular}{|c|c|c|c|c|c|}
\hline المعنوية & قالحسوبة ت & لفرضى & لأنحيارى & الحسابى & ألعراد \\
\hline 0.000 & 219.269 & $0.44 \mathrm{~S}$ & $8.79^{\prime}$ & 99.43 & 384 \\
\hline
\end{tabular}

وتتثير هذه النتيجة أن المرأة الريفية لديهن سلوك

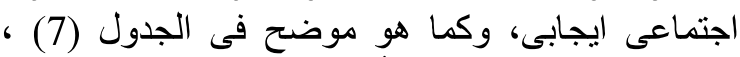

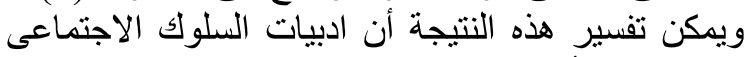

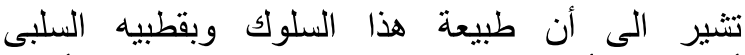

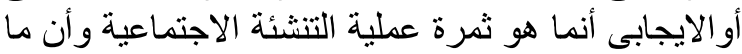

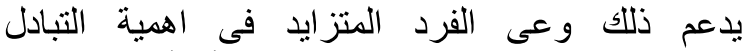

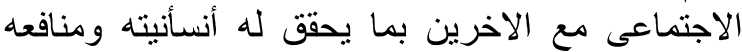

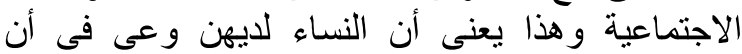

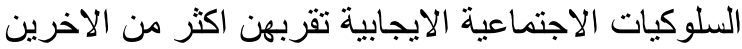

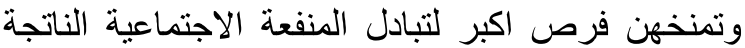

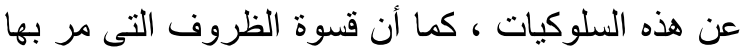

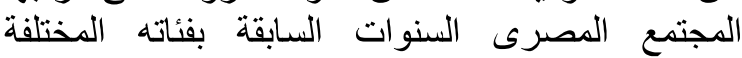

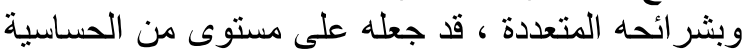

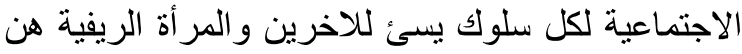

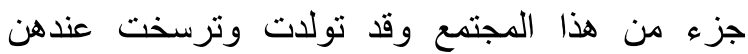

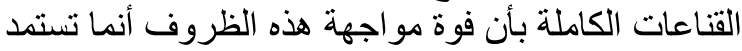

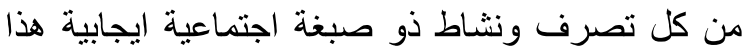

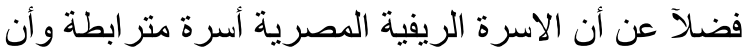

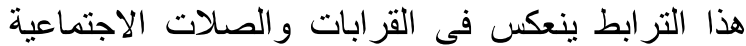

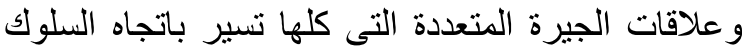
الاجتماعى الايجابيى والابتعاد عن تلأك السلوكيات ذات التيرات

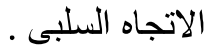

3 17 ـ العلاقة بين جودة الحياة الأسرية وأثرها على العاعي السلوك الاجتماعى لدى المبحوثين

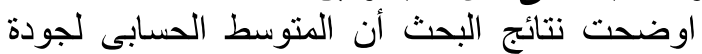
الحياة الأسرية وأثر ها على السلوك الاجتي الجتماعى للمرأة

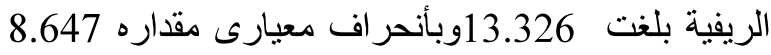
درجة ولدى اختبار دلالة الفروق بين المتوسطين باسخدام

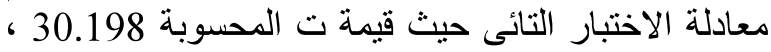
تبين أنه دال معنوياً عند مستوى دلالة 0.01

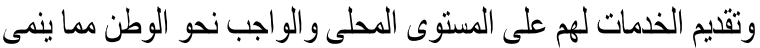

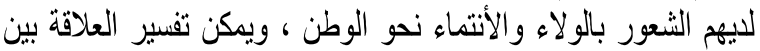

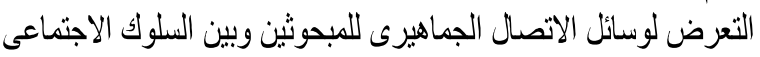

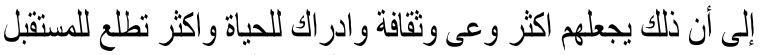

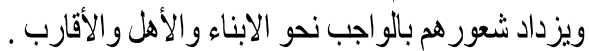

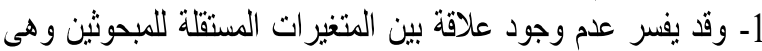

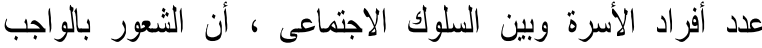

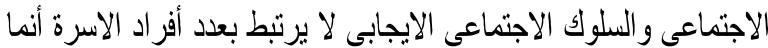

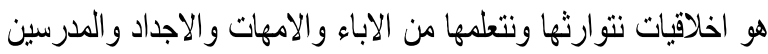
و وعلماء الاين .

2 3 ـ ق قياس جودة الحياة الأسرية لاى المبحوثين :

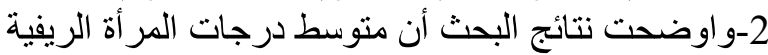
على مقياس جودة الحياة بلغت 99.43 وبأنحر افت معيارى الترى

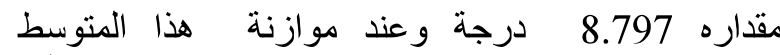
بالمتوسط الفرضى للمقياس و هو 0.799 درجة ونيان يلاحظ أنه

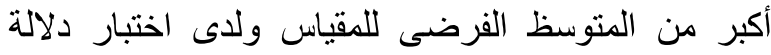

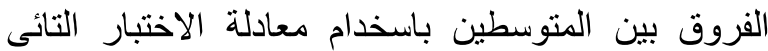
لعينة واحدة حيث قيمة ت المحسوبة بالئ 210.269 تبين أنه دال

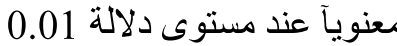
3-وتتير هذه النتيجة أن المر أة الريفية لديهن شعور آ بجودة

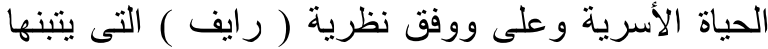
الباحث والتى تعكس المنظور الأنسأنى فأن شهور الفئ الفرد بجودة الحياة يتحقق بمقدار شعوره بالئوران بالسعادة الاستقلالية

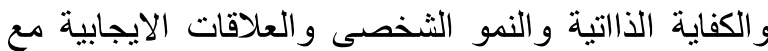

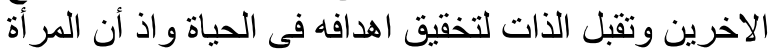

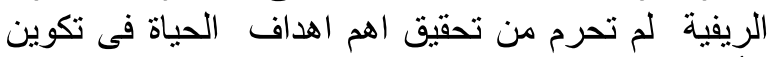

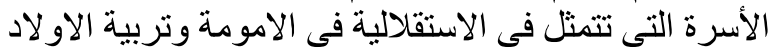

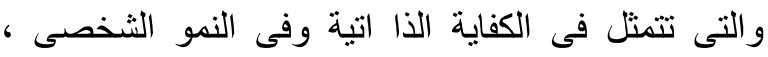

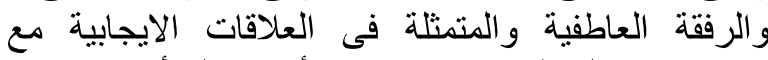

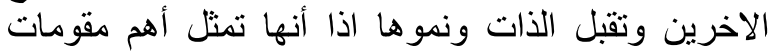
الثعور بالسعادة عند المر أة ، فأن هذا يعطى مؤشر آن آ واضخاً

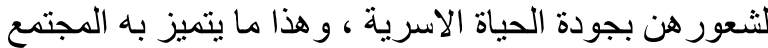

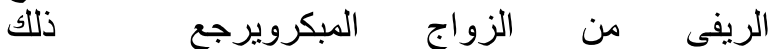
لعدم المغالاة في المهر لأنها ليست من سنة الإسلام و على الإحي

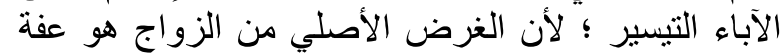

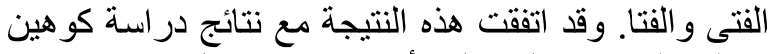

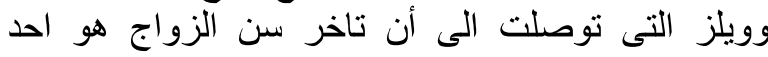

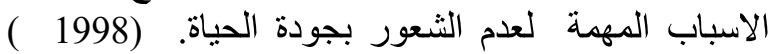
Kohen and Wills,

3 17 ـ قياس السلوك الجتماعى لاى المبحوثين :

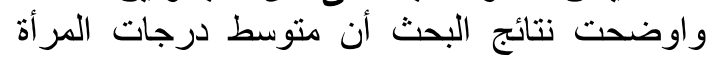
الريفية على مقياس السلوك الجتماعى بلغت 85.11 وبأنحر اف معيارى مقداره 9.843 درجة وعند موازنة

جدول (7):الاختبار التائى للفرق بين درجات مقياس السلوك الجتماعى والمتوسط الفرضى للمقياس لاى عينة البحث

\begin{tabular}{|c|c|c|c|c|c|}
\hline مستوى المعنوية & الميمة تبة & المتوسط الفرضى & الأنحراف المعيارى & المتوسط الحسابى & عدد أفراد \\
\hline 0.000 & 169.431 & 0.502 & 9.843 & 85.11 & 384 \\
\hline
\end{tabular}


T- Test الجول (8): العلاقة بين جودة الحياة الأسرية وأثرها على السلوك الاجتماعى للمر أة الريفية

\begin{tabular}{|c|c|c|c|c|}
\hline مستوى المعنوية & قيمة & الاتحراف المعيارى & المتوسط الحسابي & اجمالى المقياس \\
\hline 0.000 & 30.198 & 8.647 & 13.326 & جودة الحياة الاسرية و السلوك الاجتماعى \\
\hline
\end{tabular}

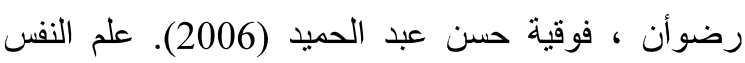

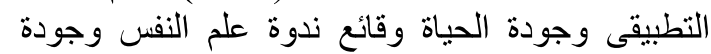
الحياة جامعة السلطأن قابوس مسقط (1984) ديسمبر لئرة

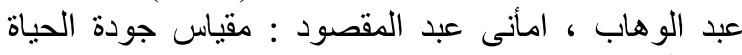

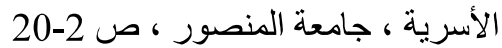

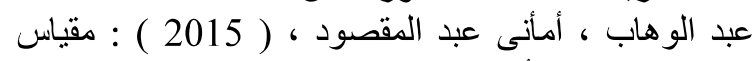

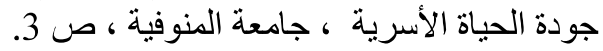

فرغلى ، علاء ء، (2006 ) : الأسرة والتربية النفسية للطفل

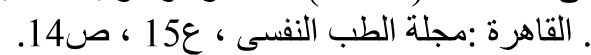

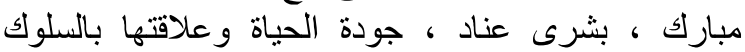

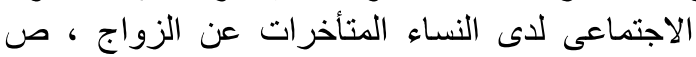

.771-766

\section{REFERENCES}

Baptista M, Baptista A, ferracini A. and Tito P. (2006). Relation Psicologica Teoria investigacaso, Epractica, II(2), pp.211-225.

Kinnier R. T., Metha A. T., Keim J. S. and Okey, J. L. (1994). Depression, meaninglessness, and substance abuse in" normal" and hospitalized adolescents. Journal of Alcohol and Drug Education.

Kohen L. B. and Wills W.T. (1998). Social behavior, Quality of life, In introduction of social psychology, L.B.T

Merrell K.W. and Ohers (1993) . The Relationship between social behavior and self concept in school sittings, Psychology in the schools, D.A.I, v.(30), N.(4) .

Parsons T. (1966) . The structure of social action, free press, NewYork, forth printing .

Rebecca R. (2000). Quality of life research unit, http// : www. U Toronto . ca (910) unit htm.

Ryff C. D. (1989). Happiness is everything, or is it? Explorations on the meaning of psychological well-being. Journal of personality and social psychology, 57(6), 1069.

Smelser N.J. (1970). The theory of collective behavior, Routledge \& Kagan Paul, Third impression, London .

Tajfel H. and Turner C.T. (2004). The Social Identity theory of Inter group behavior . in : J.T. Jost \& J. Sidanias (Eds). Political psychology . New York : Psychology press, pp.276-293.

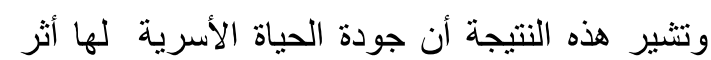

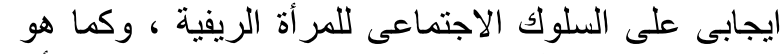

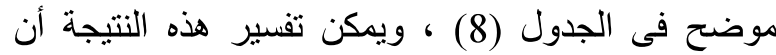

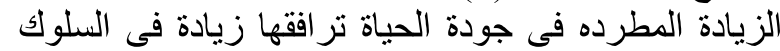

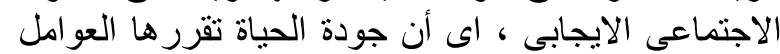

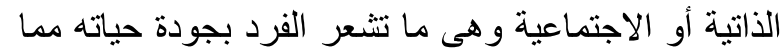

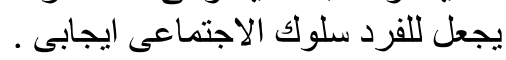
18.3

وفق ما توصل اليه البحث من نتائج فأن الباحث يضع التوصيات الاتية :

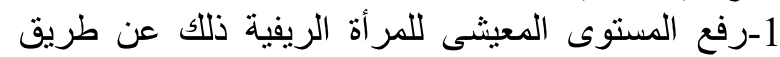

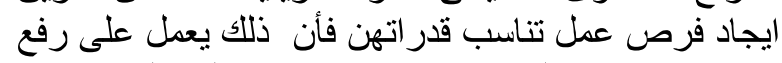

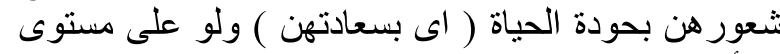

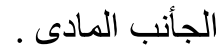

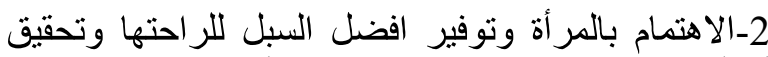

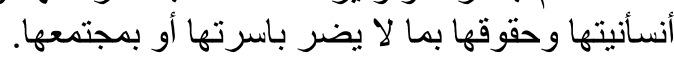

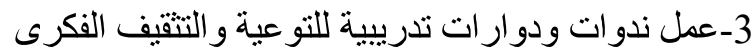

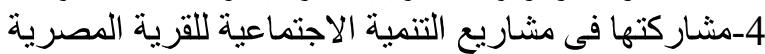
5-المشاركة فى الحياة السياسية .

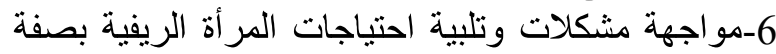

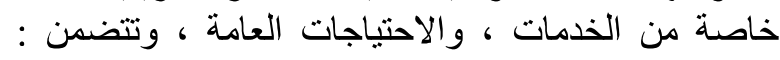
الحاجات الصحية، الحاجات الاجتماعية، الحاجات الثاتية الثقافية،

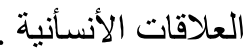

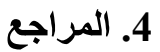

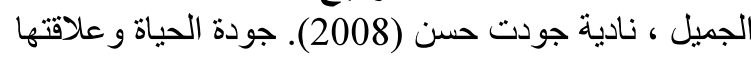

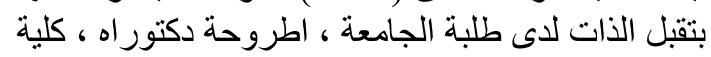

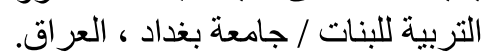

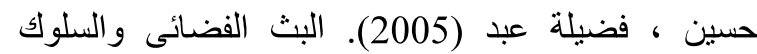

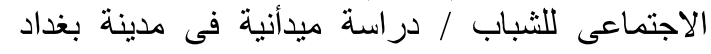

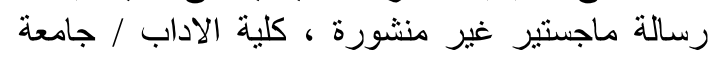
بغداد ، العراق.

الثنقيرى ، أمل (2006). دورة وزافي الارة التنمية الاجتماعية

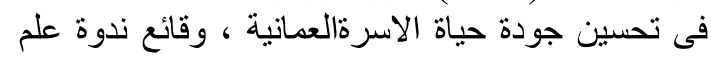

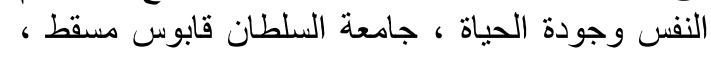

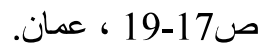

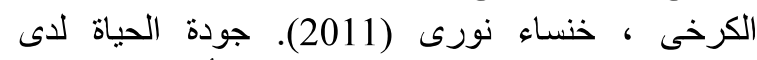

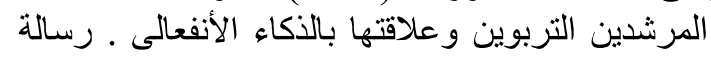

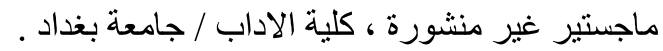

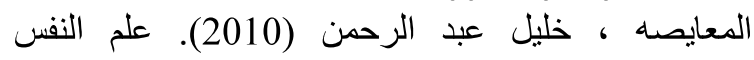
الاجتماعى ، دار الفكر ، عمان الرعن

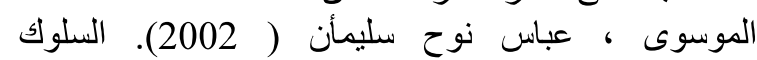
الاجتماعى وعلاقته بالثعور بالذات والات والامن النفسى لدى الدى

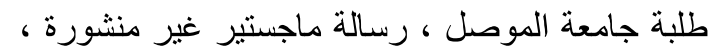
كلية التربية ، جامعة الموصل ، رسلة ، العراق . 